\title{
Distribution of blue whale populations in the southern Indian Ocean based on a decade of acoustic monitoring
}

\author{
Torterotot Maëlle ${ }^{1,}{ }^{*}$, Samaran Flore ${ }^{2}$, Stafford Kathleen M. ${ }^{3}$, Royer Jean-Yves ${ }^{4}$
}

${ }^{1}$ Laboratoire Géosciences Océan, Université de Brest, Brest, France

2 Lab-STICC, ENSTA Bretagne, Brest, France

${ }^{3}$ Applied Physics Laboratory, University of Washington, Seattle, USA

${ }^{4}$ Laboratoire Géosciences Océan, Université de Brest et CNRS, Brest, France

* Corresponding author : Maëlle Torterotot, email address : maelle.torterotot@univ-brest.fr

\begin{abstract}
:
Globally, the Indian Ocean appears to have the greatest blue whale (Balaenoptera musculus ssp) acoustic diversity, with at least four acoustic populations from three defined sub-species. To understand how these different populations use this region as habitat, we first need to characterize their spatial and seasonal distributions. Here, we build on previous passive acoustic monitoring studies and analyze a passive acoustic dataset spanning large temporal ( 9 years) and spatial ( 3 to 9 sites covering more than 12 million $\mathrm{km} 2$ of potential acoustic habitat in the southwest Indian Ocean) scales. A novel detection algorithm was employed to investigate the long-term presence of Antarctic blue whale and SEIO and SWIO pygmy blue whale calls. We found that Antarctic and pygmy blue whales have completely different spatial and seasonal distribution in the southern Indian Ocean. Antarctic blue whales are heard almost year-round on the whole array, with great inter-annual variability. The two pygmy blue whales share a highly stable seasonal acoustic presence, but their geographical distributions overlap at only a few central Indian Ocean sites. However, Antarctic and pygmy blue whale acoustic co-occurrence is common, especially in sub-tropical waters. These temporal and spatial distributions strengthen our understanding of seasonal occurrence and habitat use of distinct populations of blue whales in the southern Indian Ocean. A better comprehension of the ecology of Indian Ocean blue whales will require interdisciplinary studies to examine the drivers of the variability seen from passive acoustic studies.
\end{abstract}

Keywords : Antarctic blue whale, pygmy blue whale, passive acoustics, population distribution 


\section{${ }_{34} 2$ Introduction}

${ }_{35}$ The Indian Ocean, particularly its southern extent, is one of the oceans with the greatest blue

36 whale acoustic diversity (McDonald et al., 2006). As a response to extensive commercial whaling

37 in both the Southern and Indian Oceans which greatly depleted numbers of blue whales, in

381979 the International Whaling Commission (IWC) created the Indian Ocean Whale Sanctuary

39 (IOWS), the first ever region where commercial whaling was banned for all species(IWC, 1980).

40 Three blue whale subspecies are seasonally present in the Indian Ocean: the Antarctic blue

${ }_{41}$ whale (Balaenoptera musculus intermedia) and the pygmy blue whales (B. m. brevicauda 
body size and acoustic signatures (Ichihara, 1966: LeDuc et al., 2007, Ljungblad et al., 1998). Furthermore, at least three distinct populations of pygmy blue whales have been identified: the Northwestern (NWIO), Southwestern (SWIO) and Southeastern (SEIO) pygmy blue whale populations (Stafford et al., 2011). Whereas the Antarctic blue whale has been declared as an endangered species by the IUCN (International Union for the Conservation of Nature), the status of the pygmy blue whales is unknown and therefore considered 'data deficient' by the IUCN (Cooke, 2019). Monitoring blue whales remains a challenge due to the scarcity of individuals and to the extent and location of their habitat, largely encompassing remote and inaccessible regions of the ocean. Moreover, identifying pygmy from Antarctic blue whales by visual observation is very difficult, as they look almost identical, despite the smaller length of pygmy blue whales (Ichihara, 1966). Thus, most of the knowledge about blue whales in the Indian Ocean comes from whaling data (Branch et al., 2007, 2009), and from passive acoustic monitoring (Samaran et al., 2010a; Stafford et al., 2011; Samaran et al., 2013; Leroy et al., 2016; Dréo et al., 2018). Blue whales are particularly good candidates for this type of observation, because of their repetitive, long (more than 15 seconds), loud (more than $180 \mathrm{~dB}$ ref $1 \mathrm{uPa}$ at $1 \mathrm{~m})$ and low frequency $(20-100 \mathrm{~Hz})$ calls (Cummings and Thompson, 1971). Blue whale calls vary from one region to another and have been used to tell apart different blue whale subspecies and acoustic populations (McDonald et al., 2006). In the southern Indian Ocean, calls of Southeastern Indian Ocean (Figure 1 a) and Southwestern Indian Ocean (Figure 1 b) pygmy blue whale populations as well as Antarctic blue whale calls (Figure 1 c) have clear distinct characteristics that are readily observed in the spectogram (McCauley et al. 2000, Samaran et al., 2010a; Stafford et al., 2011).

Whaling data depicted baleen whale migration as being a consistent movement between productive feeding grounds at high latitudes in summer, and breeding grounds at lower latitudes in winter (Kellogg, 1929, Mackintosh, 1942, 1966). However, year-round captures and sightings of Antarctic blue whales in whaling grounds at high or low latitudes suggest more complex migratory behaviors (Harmer, 1931, Branch et al., 2007). In agreement with these findings, evidence of year-round acoustic presence of Antarctic blue whales off Antarctica (Širović et al. 2014: Thomisch et al. 2016) and Namibia (Thomisch et al., 2019), and observations of foraging 

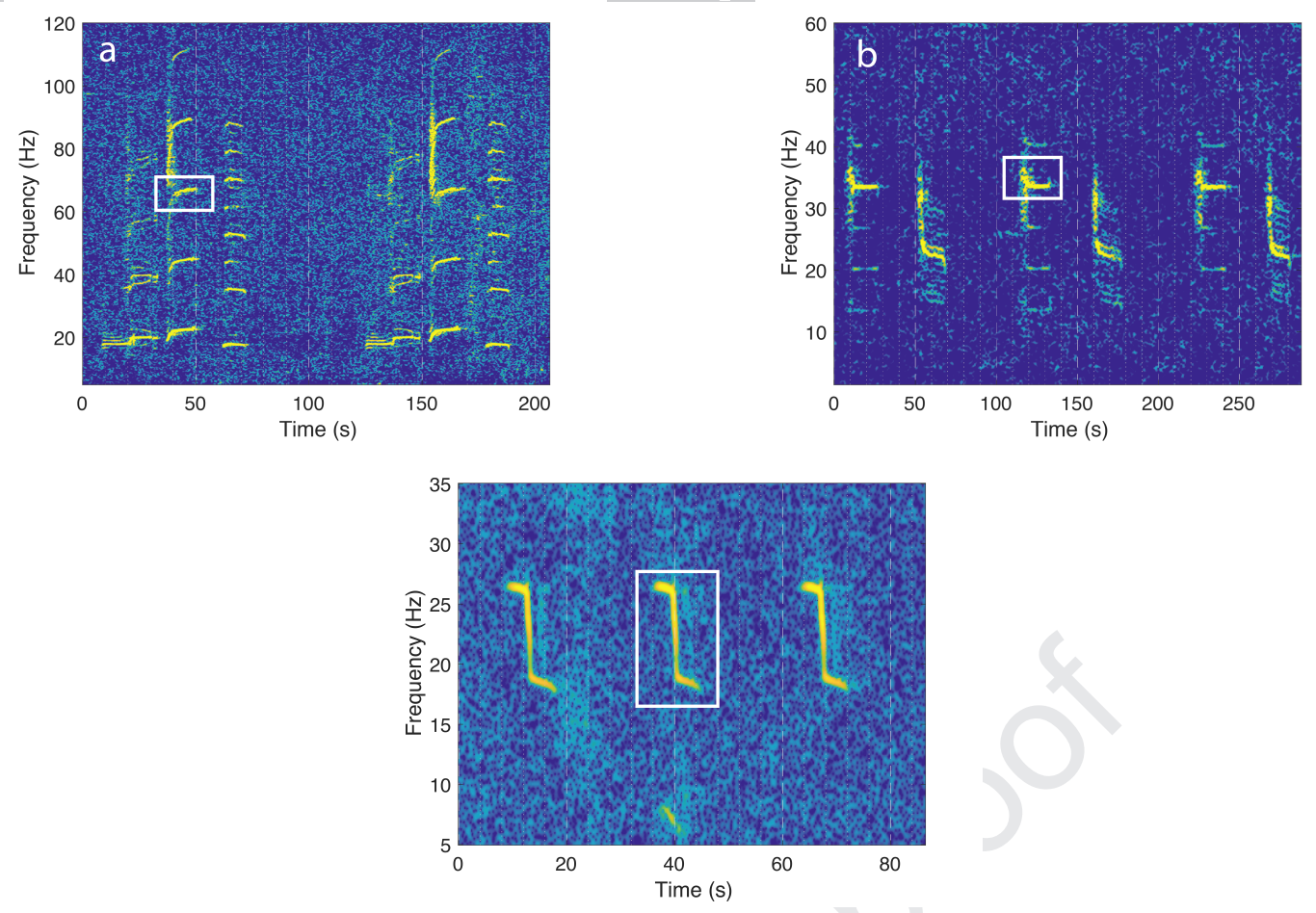

Figure 1: Typical spectrograms of (a) Southeastern Indian Ocean pygmy blue whale calls (b) Southwestern Indian Ocean pygmy blue whale calls, and (c) Antarctic blue whale calls from the Southern Indian Ocean

behavior en route towards summer feeding grounds (Visser et al., 2011) supports the idea of a more complex migratory pattern. For instance, skipping migration to remain at feeding grounds may benefit individuals to maximize their growth and body mass (Shaw and Levin, 2011). In the southern Indian Ocean, Antarctic blue whale calls are detected year-round, with a lesser presence during austral summer and a shift from subantarctic locations in austral autumn to subtropical locations in the austral winter and back to subantarctic locations in spring (September to November) (Stafford et al., 2004; Samaran et al., 2010a, 2013; Leroy et al., 2016). This seasonal pattern is generally stable over the years, but some variations suggest that the migration routes are flexible (Samaran et al., 2010a, 2013, Leroy et al., 2016). In contrast, pygmy blue whales present a totally different migration pattern. Short-term (Stafford et al. 2011; Samaran et al., 2013) and broad-scale acoustic studies based on the chorus intensity (intensity within the call frequency band) depict a longitudinal differentiation of the SEIO and SWIO pygmy blue whale populations. The former are mainly present in the eastern Indian Ocean and the latter in the western Indian Ocean. Yet, they seem to share a common seasonality with an acoustic presence during all seasons except spring Stafford et al., 2011; Samaran et al., 2013; Leroy et al., 2018b). 
Iournal Pre-nron

Despite their different distribution, SEIO and SWIO pygmy blue whales have both been

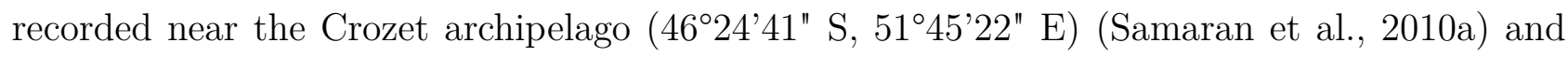

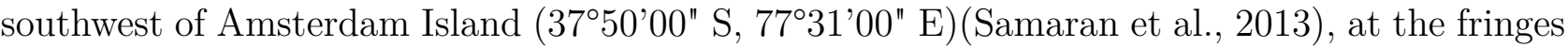
of their respective habitat (see map in Figure 2). Similar co-occurence of pygmy blue whales (SEIO and southwestern Pacific populations) has been reported in the Bass Strait, between mainland Australia and Tasmania (McCauley et al., 2018), which marks the geographical barrier between these two populations Balcazar et al. (2015). Sympatric acoustic presence of Antarctic and pygmy blue whales has also been observed off southern Australia (Tripovich et al., 2015), near the Crozet archipelago (Samaran et al., 2010a), in the Madagascar Basin, north and south of Amsterdam Island (Samaran et al., 2013) and in the north of the Mozambique Channel (Cerchio et al., 2018).

The function of songs for blue whales is not unanimously agreed upon. The fact that only males are thought to sing (Oleson et al., 2007, Lewis et al., 2018) as well as the seasonal repetition, high source levels (McDonald et al., 2001: Širović et al., 2007; Samaran et al., 2010b) and the long durations of the calls, point to a reproductive purpose (McDonald et al., 2001. Oleson et al., 2007). Acoustic co-occurrence of different sub-species may therefore indicate potential inter-subspecies breeding areas or the use of song to isolate different populations from interbreeding (Stafford and Moore, 2005). However, the year-round detection of songs at high-latitude feeding areas (Stafford et al., 2001, Širović et al., 2004, 2009: Thomisch et al. 2016) suggests that the calls may play additional roles, such as assisting in navigation and prey detection (Clark and Ellison, 2004), or promoting the formation of pairs(Lewis et al. 2018; Oleson et al., 2007). Acoustic co-occurrence of multiple sub-species may also simply reflect differing ecological strategies and/or habitat use by each subspecies, such as off Southern Australia, which would be a migratory corridor for Antarctic blue whales and a feeding ground for the SEIO pygmy blue whales (Tripovich et al., 2015).

To progress in our understanding of these concepts, this work presents a detailed analysis of the seasonal and spatial presence of Antarctic and pygmy blue whales, based on 9 years of continuous acoustic recordings (2010-2018) at multiple sites across the southern Indian Ocean. Relative to previous analyses, we provide a longer time series and new recording locations. We also base our analysis on the systematic detection of pygmy blue whale calls, when former stud- 
Joumal Pre-proof

ies only looked at the chorus power to describe their acoustic presence. The comparison between these two passive acoustic monitoring metrics is then discussed. These data yield a clearer picture on the seasonal acoustic presence of pygmy and Antarctic blue whales and spatially how they share the IWC IOWS. This information is essential for improving the management and conservation of the world's largest animal.

\section{Material and methods}

\subsection{Data acquisition}

The acoustic data used in this study were recorded by the OHASISBIO (Observatoire HydroAcoustique de la SISmicité et de la Biodiversité; Royer (2009)) hydrophone network, located in the southwest Indian Ocean (see Figure 2). The network was deployed in December 2009 and is still recording as of the date of publication. Between 2009 and 2016, it comprised 5 permanent mooring sites, located south of La Réunion Island (MAD), north of Crozet archipelago (NCRO), west of Kerguelen Island (WKER) and southwest and northeast of St Paul and Amsterdam islands (SWAMS and NEAMS). In 2012-2013, a mooring was temporarily deployed near the Equator, in the Central Indian Basin, east of Diego Garcia archipelago (RAMA) and since 2014, a new site was instrumented, south of the southeast Indian Ridge (SSEIR). In 2017, the network geometry was slightly modified to improve the coverage of the northern areas and refine the location of blue-whale wintering grounds, with three new sites RTJ, MAD-W and MAD-E, the latter two on either side of the initial MAD site. The new site S-SWIR, south of the southwest Indian ridge, replaced the NCRO site and an additional mooring (ELAN) was installed at $56^{\circ} \mathrm{S}$, south of Kerguelen plateau, to complete the spatial coverage southward. The MAD and NCRO moorings are no longer deployed.

Each mooring is composed of an anchor, an acoustic release, an adjustable length of line and a submerged buoy containing the recording system. The instruments are moored between $1000 \mathrm{~m}$ and $1300 \mathrm{~m}$ depth, corresponding to the local sound fixing and ranging (SOFAR) channel axis. The SOFAR works like a waveguide, where low frequency sounds can propagate over very long distances (Lurton, 2002). The instruments record continuously at a sampling rate of 


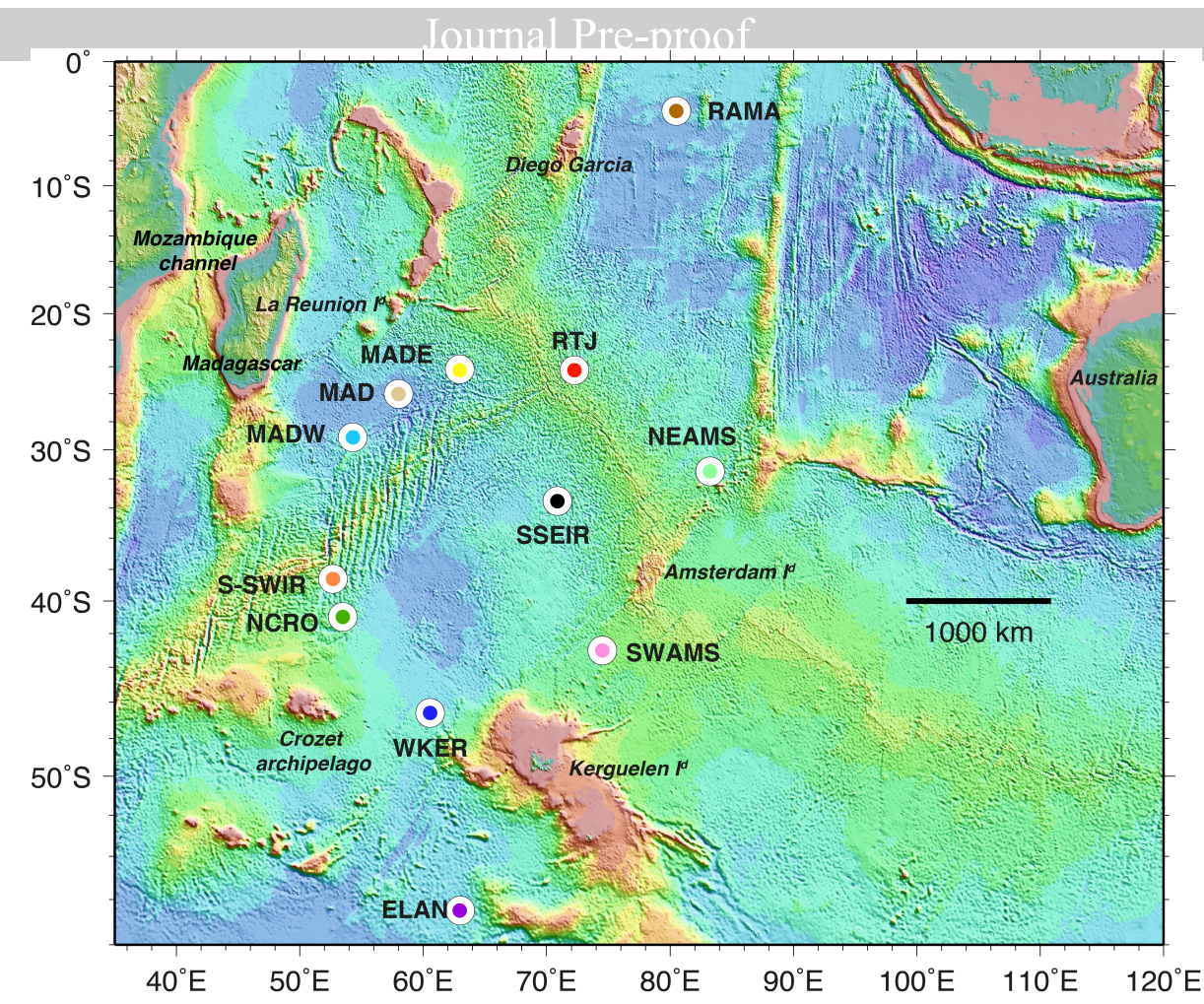

Figure 2: The OHASISIBIO hydrophone network in the Southern Indian ocean. Colored dots represent mooring sites.

$240 \mathrm{~Hz}$ using a 24-bit analog-to-digital conversion and the recorded data are archived on the instrument (d'Eu et al. 2012).

The moorings are turned around annually and the data are collected every January/February during the annual scientific cruise of R/V Marion Dufresne to the French Southern and Antarctic Territories in the southern Indian Ocean. The current database comprises almost continuous acoustic records over 9 years (from 2010 to 2018), with some gaps mostly due to unexpected battery exhaustion. Table 1 summarizes the site coordinates and the recording periods of the data used in this study. The first six lines correspond to the long-term monitoring sites, and the last six lines to the short-term monitoring sites.

\subsection{Acoustic data processing}

The metrics used here to assess blue whale acoustic presence are the number of calls detected per week, month or year. For pygmy blue whale calls with multiple units, a single unit was detected, either because it was the loudest unit of the call or because its frequency did not overlap with that of other blue whale calls (selected units are outlined by white rectangles in 
Journal Pre-proo

Table 1: Details of the OHASISBIO deployments with: mooring name; latitude and longitude ; starting and ending recording date. A "-" indicates continuous recording without data recovery ; an " $x$ " sign indicates absence of data.

\begin{tabular}{|c|c|c|c|c|c|c|c|c|c|c|c|c|c|c|c|c|c|c|c|}
\hline \multirow{2}{*}{ Site } & \multirow{2}{*}{ Geo. Coor. } & \multicolumn{2}{|c|}{2010} & \multicolumn{2}{|c|}{2011} & \multicolumn{2}{|c|}{2012} & \multicolumn{2}{|c|}{2013} & \multicolumn{2}{|c|}{2014} & \multicolumn{2}{|c|}{2015} & \multicolumn{2}{|c|}{2016} & \multicolumn{2}{|c|}{2017} & \multicolumn{2}{|c|}{2018} \\
\hline & & Start & Stop & Start & Stop & Start & Stop & Start & Stop & Start & Stop & Start & Stop & Start & Stop & Start & Stop & Start & Stop \\
\hline MAD & $\begin{array}{l}26^{\circ} 05 \mathrm{~S}, \\
058^{\circ} 08^{8} \mathrm{E}\end{array}$ & 20/12/09 & $19 / 02 / 11$ & $19 / 02 / 11$ & 09/03/12 & $10 / 03 / 12$ & $09 / 03 / 13$ & $09 / 03 / 13$ & $16 / 02 / 14$ & $16 / 02 / 14$ & $18 / 01 / 15$ & $18 / 02 / 15$ & $28 / 01 / 16$ & $29 / 01 / 16$ & $09 / 01 / 17$ & $\mathrm{x}$ & $\mathrm{x}$ & $\mathrm{x}$ & $\mathrm{x}$ \\
\hline NEAMS & $\begin{array}{l}31^{\circ}{ }^{\circ} 5^{\mathrm{S}} \mathrm{S} \\
083^{\circ} 14^{\prime} \mathrm{E}\end{array}$ & $13 / 02 / 10$ & - & - & $25 / 11 / 11$ & $04 / 03 / 12$ & $04 / 03 / 13$ & $04 / 03 / 13$ & $10 / 02 / 14$ & $\mathrm{x}$ & $\mathrm{x}$ & $4 / 02 / 15$ & $25 / 08 / 15$ & $\mathrm{x}$ & $\mathrm{x}$ & $31 / 01 / 17$ & $05 / 02 / 18$ & $05 / 02 / 18$ & $29 / 01 / 19$ \\
\hline SSEIR & $\begin{array}{l}33^{\circ} 30^{\circ} \mathrm{S}, \\
70^{\circ} 30^{\circ} \mathrm{E},\end{array}$ & $\mathrm{x}$ & $\mathrm{x}$ & $\mathrm{x}$ & $\mathrm{x}$ & $\mathrm{x}$ & $\mathrm{x}$ & $\mathrm{x}$ & $\mathrm{x}$ & $13 / 02 / 14$ & $04 / 02 / 15$ & $05 / 02 / 15$ & $18 / 01 / 16$ & $25 / 01 / 16$ & $04 / 02 / 17$ & $04 / 02 / 17$ & $08 / 02 / 18$ & $08 / 02 / 18$ & $23 / 12 / 18$ \\
\hline NCRO & $\begin{array}{l}41^{\circ} 00^{\circ} \mathrm{S}, \\
52^{\circ} 49^{\prime} \mathrm{E}\end{array}$ & $\mathrm{x}$ & $\mathrm{x}$ & $20 / 01 / 11$ & $30 / 01 / 12$ & $29 / 01 / 12$ & $10 / 02 / 13$ & $\mathrm{x}$ & $\mathrm{x}$ & $11 / 01 / 14$ & $11 / 01 / 15$ & $11 / 01 / 15$ & $08 / 01 / 16$ & $08 / 01 / 16$ & $06 / 06 / 16$ & $x$ & $\mathrm{x}$ & $\mathrm{x}$ & $\mathrm{x}$ \\
\hline SWAMS & $\begin{array}{l}42^{\circ} 59^{\circ} \mathrm{S}, \\
74^{\circ} 35^{\circ} \mathrm{E}\end{array}$ & $\mathrm{x}$ & $\mathrm{x}$ & $\mathrm{x}$ & $\mathrm{x}$ & $29 / 02 / 12$ & $27 / 02 / 13$ & $28 / 02 / 13$ & $07 / 02 / 14$ & $07 / 02 / 14$ & $27 / 01 / 15$ & $27 / 01 / 15$ & $20 / 01 / 16$ & $21 / 01 / 16$ & $01 / 08 / 16$ & $\mathrm{x}$ & $\mathrm{x}$ & $31 / 01 / 18$ & $30 / 01 / 19$ \\
\hline WKER & $\begin{array}{l}46^{\circ} 38^{\prime} \mathrm{S} \\
60^{\circ} 07^{\prime} \mathrm{E}\end{array}$ & $28 / 12 / 09$ & $24 / 01 / 11$ & $25 / 01 / 11$ & $03 / 02 / 12$ & $04 / 02 / 12$ & $14 / 02 / 13$ & $15 / 02 / 13$ & $15 / 01 / 14$ & $15 / 01 / 14$ & $01 / 01 / 15$ & $16 / 01 / 15$ & $01 / 08 / 16$ & $12 / 01 / 16$ & $20 / 01 / 17$ & $20 / 01 / 17$ & $19 / 01 / 18$ & $19 / 01 / 18$ & $28 / 07 / 18$ \\
\hline RAMA & $\begin{array}{l}03^{\circ} 50^{\prime} \mathrm{S} \\
80^{\circ} 30^{\prime} \mathrm{E}\end{array}$ & $\mathrm{x}$ & $\mathrm{x}$ & $\mathrm{x}$ & $\mathrm{x}$ & $05 / 05 / 12$ & - & - & $11 / 12 / 13$ & $\mathrm{x}$ & $\mathrm{x}$ & $\mathrm{x}$ & $\mathrm{x}$ & $\mathrm{x}$ & $\mathrm{x}$ & $\mathrm{x}$ & $\mathrm{x}$ & $\mathrm{x}$ & $\mathrm{x}$ \\
\hline RTJ & $\begin{array}{l}24^{\circ} 15^{\mathrm{S}} \mathrm{S} \\
72^{\circ} 15^{\prime} \mathrm{E}\end{array}$ & $\mathrm{x}$ & $\mathrm{x}$ & $\mathrm{x}$ & $\mathrm{x}$ & $\mathrm{x}$ & $\mathrm{x}$ & $\mathrm{x}$ & $\mathrm{x}$ & $\mathrm{x}$ & $\mathrm{x}$ & $\mathrm{x}$ & $\mathrm{x}$ & $\mathrm{x}$ & $\mathrm{x}$ & $\mathrm{x}$ & $\mathrm{x}$ & $11 / 02 / 18$ & $10 / 02 / 19$ \\
\hline MAD-E & $\begin{array}{l}24^{\circ} 11^{\prime} \mathrm{S}, \\
63^{\circ} 01^{\prime} \mathrm{E}\end{array}$ & $\mathrm{x}$ & $\mathrm{x}$ & $\mathrm{x}$ & $\mathrm{x}$ & $\mathrm{x}$ & $\mathrm{x}$ & $\mathrm{x}$ & $\mathrm{x}$ & $\mathrm{x}$ & $\mathrm{x}$ & $\mathrm{x}$ & $\mathrm{x}$ & $\mathrm{x}$ & $\mathrm{x}$ & $07 / 02 / 17$ & $13 / 02 / 18$ & $13 / 02 / 18$ & $21 / 07 / 18$ \\
\hline MAD-W & $\begin{array}{l}29^{\circ} 03^{\prime} \mathrm{S}, \\
54^{\circ} 16^{\prime} \mathrm{E}\end{array}$ & $\mathrm{x}$ & $\mathrm{x}$ & $\mathrm{x}$ & $\mathrm{x}$ & $\mathrm{x}$ & $\mathrm{x}$ & $\mathrm{x}$ & $\mathrm{x}$ & $\mathrm{x}$ & $\mathrm{x}$ & $\mathrm{x}$ & $\mathrm{x}$ & $\mathrm{x}$ & $\mathrm{x}$ & $06 / 01 / 17$ & $06 / 01 / 18$ & $06 / 01 / 18$ & $3 / 11 / 18$ \\
\hline S-SWIR & $\begin{array}{l}38^{\circ} 33^{\prime} \mathrm{S}, \\
52^{\circ} 53^{\circ} \mathrm{E}\end{array}$ & $\mathrm{x}$ & $\mathrm{x}$ & $\mathrm{x}$ & $\mathrm{x}$ & $\mathrm{x}$ & $\mathrm{x}$ & $\mathrm{x}$ & $\mathrm{x}$ & $\mathrm{x}$ & $\mathrm{x}$ & $\mathrm{x}$ & $\mathrm{x}$ & $\mathrm{x}$ & $\mathrm{x}$ & 08/01/17 & $22 / 12 / 17$ & $09 / 01 / 18$ & $14 / 01 / 19$ \\
\hline ELAN & $\begin{array}{l}56^{\circ} 28^{8} \mathrm{~S}, \\
62^{\circ} 59^{\circ} \mathrm{E}\end{array}$ & $\mathrm{x}$ & $\mathrm{x}$ & $\mathrm{x}$ & $\mathrm{x}$ & $\mathrm{x}$ & $\mathrm{x}$ & $\mathrm{x}$ & $\mathrm{x}$ & $\mathrm{x}$ & $\mathrm{x}$ & $\mathrm{x}$ & $\mathrm{x}$ & $\mathrm{x}$ & $\mathrm{x}$ & $\mathrm{x}$ & $\mathrm{x}$ & $16 / 01 / 18$ & $23 / 01 / 19$ \\
\hline
\end{tabular}

Figure 1). For Antarctic blue whales, the whole call was used for detection (Figure 1 1 c). For the SEIO pygmy blue whales, we selected the most powerful harmonic at $70 \mathrm{~Hz}$ (Figure $1 \mathrm{a}$ ). For the SWIO pygmy blue whales, we selected the $35 \mathrm{~Hz}$ unit (Figure 1 b), to avoid overlap with the Antarctic blue whale chorus. The chorus is the elevation of the noise in specific frequency bands produced by the accumulation of numerous distant calls overlapping ( Širović et al., 2009. Thomisch et al. 2016).

\subsubsection{Automated call detection}

To facilitate the time-consuming and tedious task of manually detecting calls, an automated detection algorithm based on dictionary learning and sparse representation of blue whale vocalizations was used (Socheleau and Samaran, 2018). The principal asset of this method lies in the alliance of large dictionaries, which take call variability into account, with linear combinations of several elements of those dictionaries, to reflect call complexity. The detector does not require an a priori fixed template, but works with dictionaries built from temporal call signals directly extracted from the data. It then tries to reconstitute the observed signal with sparse combinations of the waveforms contained in the dictionary. The better the signal is reconstructed, the higher the resemblance metric (Socheleau and Samaran, 2018, Guilment et al. 2018).

In such an endeavor, the difficulty is to avoid the detection of interfering signals and therefore 
to avoid a time-consuming double check of each detection - while keeping a reasonable recall, at least for high Signal to Noise Ratio (SNR) calls which are more likely to come from whales close to the hydrophone. To achieve this goal, the algorithm was tested on a large manually annotated data subset containing recordings from different seasons and locations of the OHASISBIO array. A threshold corresponding to one false positive detection per hour was set and the corresponding recall reached $90 \%$ for positive SNR calls (Torterotot et al., 2019). The detector was then tested on an entire year of data (2015) at WKER site and every detection was manually double checked, to characterize any interferences that could fool the algorithm and to re-evaluate the false alarm rate in case of call absence. Most interferences are due to chorus, especially for SWIO pygmy blue whale calls. Other interference categories include ship noise and unknown continuous noise within the call frequency band. The number of false positive detections was stable across different abundance scenarios (i.e. periods of high and low call presence) and was far below the theoretical one-false-positive-detection-per-hour rate initially defined. The different annotation procedures (i.e. manual annotation then automated detection versus automated detection then manual double-check) might explain these variabilities. To account for the annual linear pitch decrease of blue whale calls (Gavrilov et al., 2011, 2012; Leroy et al., 2018a), a new dictionary was built for every year from the detector outputs based on a dictionary from a contiguous year. The performance evaluation of the algorithm on the same data used in this paper is thoroughly discussed in Torterotot et al. (2019).

\subsection{Detection results analysis}

Recordings with a small number of annual detections were manually double checked to assess whether or not these few detections accurately illustrated a blue whale acoustic presence. For SEIO pygmy blue whale calls, ELAN, MAD, SSEIR, MAD-E, MAD-W, NCRO, RTJ, S-SWIR and RAMA sites were double-checked ; for SWIO pygmy blue whale calls, ELAN, SSEIR, RTJ and RAMA sites were double-checked ; for Antarctic blue whale calls only RAMA site was double checked. If most of the detections were false alarms, the annual number of detections was set to 0 , otherwise, all the detections were left as is.

Seasonal occurrence is presented as the absolute number of detections per week, for every 
week with more than 6 days of recording. Weeks with fewer than 6 days are considered as incomplete and the results are not presented. To study the inter-annual variability of the acoustic seasonal pattern, we used the Pearson correlation coefficient, a non-parametric test that is used to measure whether or not a correlation (i.e. linear relationship) exists between call distribution from two consecutive years. To assess quantitatively how the different subspecies share a recording site, we compared their seasonal pattern using Spearman's correlation coefficients. This statistic tests whether or not a correlation (i.e. monotonic relationship) exists between the seasonal presence of two blue whale acoustic populations. For both correlation tests (Pearson's and Spearman's), only the results with a $p$ value $<0.05$, meaning that the null hypothesis cannot be rejected, will be reported.

Sympatry is defined as the number of hours per month with multiple acoustic blue whale populations detected normalized by the total number of recorded hours that same month over the whole recording period (2010-2018). To avoid taking too many false detections into account, a call type is considered detected when there was more than one detection within an hour.

Austral seasons are defined as follows: summer (December, January, February), autumn (March, April, May), winter (June, July, August), and spring (September, October, November).

Results at sites NCRO and S-SWIR are combined in the same figure for the sake of space: from 2011 until 2016 they refer to NCRO data and for 2017 and 2018 to S-SWIR data. Results for the long-term sites are illustrated in Figures 3 and 4, whereas results for the short-term sites are given in Table 2 or in the appendices.

\section{Results}

\subsection{Spatial distribution and long term trends}

Figure 3 displays the number of detected calls per year for the long-term recording sites (rows) and the three blue whale calls (columns). Since blue whale acoustic presence is highly seasonal, normalizing the number of detections per year by the number of days of recording could lead to some misinterpretation, especially regarding pygmy blue whales. For example, at site WKER 
the number of SWIO pygmy blue whale calls is similar in 2017 and in 2018. However the hydrophone only lasted 6 months in 2018, from January to mid-July. Usually SWIO pygmy blue whale calls are detected during the first 6 months of the year, so the number of calls at WKER in 2017 and 2018 is similar. If the number of detections had been normalized, it would have appeared that more calls were detected in 2018 than in 2017. Instead of normalizing the number of calls per year by the recording duration, we show the actual detection number (color bars) and the number of days of recording per year (black dots). For the short-term recording sites, the results are given in Table 2 and in Appendix 1, except for RAMA which did not contained any detections.

Table 2: Number of detected calls per year for each blue whale acoustic population at the short term OHASISBIO sites. The effort is in days per year with recordings.

\begin{tabular}{|c|c|c|c|c|c|c|c|c|c|c|c|c|c|c|c|c|}
\hline & \multicolumn{4}{|c|}{ RTJ } & \multicolumn{4}{|c|}{ MAD-E } & \multicolumn{4}{|c|}{ MAD-W } & \multicolumn{4}{|c|}{ ELAN } \\
\hline & Antarctic & SEIO & SWIO & Effort & Antarctic & SEIO & SWIO & Effort & Antarctic & SEIO & SWIO & Effort & Antarctic & SEIO & SWIO & Effort \\
\hline 201 & 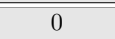 & $\overline{0}$ & $\overline{0}$ & $\overline{0}$ & 11707 & 507 & 8 & $\overline{322}$ & & $\overline{0}$ & 28 & 35 & & 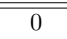 & 0 & 0 \\
\hline 2018 & 11567 & 198 & 0 & 324 & 3008 & 460 & 9394 & 197 & 36569 & 0 & 34888 & 302 & 11352 & 124 & 7481 & 345 \\
\hline
\end{tabular}

Antarctic blue whale calls were detected at all the OHASISBIO recording sites except at RAMA (Figure 3, Table 2). Overall, higher numbers of detections per year occurred at MADW and NEAMS sites, with the highest number of detections at NEAMS in $2013(\mathrm{n}=47097)$. The annual number of detections was also very high at SWAMS and WKER, whereas fewer detections were reported at SSEIR, NCRO and MAD ( $\mathrm{n}<21$ 000), except in 2014 when the number of detections at MAD doubled $(\mathrm{n}=43$ 110). Number of detections were reduced at RTJ, MAD-E and ELAN ( $\mathrm{n}<12$ 000), although only one or two years of data were available. At NEAMS, the annual number of detections increased from 2010 to 2013, and then appeared to have reached a plateau of about 40000 calls per year. At WKER, the annual number of detections per year was steady, with two small peaks in 2012 and 2014. At SWAMS and NCRO, the number of detections does not follow any obvious trend. At MAD, the annual number of detections was steady, except for peak in 2014 with almost twice as many detections as for any of the other years. There were no peaks in detections at the other sites. Globally, the annual number of Antarctic blue whale call detections did not follow any clear systematic trend or pattern.

SEIO pygmy blue whales were present at all sites of the hydrophone array, except at RAMA 

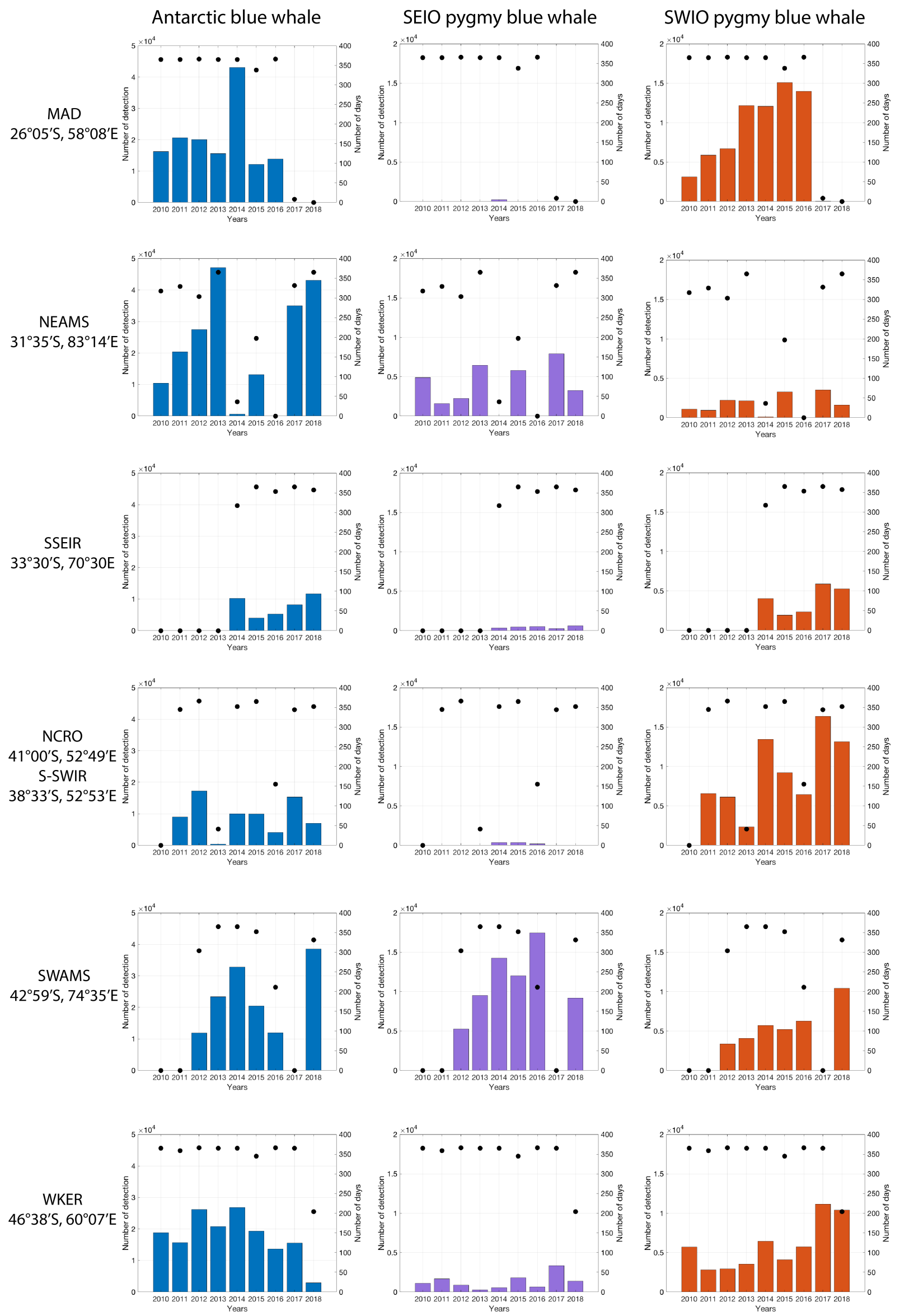

Figure 3: Number of detected calls per year (left y-axis). Each row corresponds to a different site and each column to a different call type. The sites are displayed from north to south. Black dots represent the number of days of recording for each year (right y-axis). 
and MAD-W (Figure 3, Table 2). However, for some sites, detections were scarce and limited to specific years ; for instance calls were only detected in 2014 for MAD and in 2014, 2015, and 2016 for NCRO. The site with the highest number of detections was SWAMS, followed by NEAMS and then WKER. The SSEIR site had detections of SEIO pygmy blue whale calls every year, but in very small numbers (from 258 in 2017 to 627 in 2018). Similarly, only a few calls were detected at RTJ, MAD-W and ELAN. Over the years, for NEAMS, WKER and SSEIR, the number of calls detected per year does not follow any particular trend. However, at SWAMS, the number of detections significantly increased from 2012 to 2016 (5226 up to 17453 , resp.) and diminished in 2018 (9188), although the number of recording days was less in 2016 (Figure 3).

SWIO pygmy blue whale calls were recorded at all the OHASISBIO sites except at RTJ, with only a few barely detectable calls (i.e. with very low SNR) in the chorus, and RAMA (Figure 3, Table 2). At MAD-W, even though only two years of data are available, the number of detections per year $(\mathrm{n}>28000)$ was almost double that of any other site. The long-term sites where SWIO pygmy blue whale calls were most commonly detected were MAD and NCRO, at the western side of the OHASISBIO hydrophone array. Conversely, NEAMS and SSEIR displayed fewest detections per year $(\mathrm{n}<6$ 000). At MAD site, the annual number of detections steadily increased from 2010 to 2015, from fewer than 3000 calls per year to more than 15000 . At SWAMS, the annual number of calls was more modest but also increased, doubling from 3387 calls in 2012 to 6279 in 2018. At the other sites, NCRO, NEAMS, SSEIR and WKER, there was no clear trend in the annual number of SWIO pygmy blue whale detections.

\subsection{Seasonal distribution and inter-annual variability}

The seasonal acoustic presence of Antarctic and both pygmy blue whales is shown in Figure 4 for the six long-term monitoring sites. The observations for the short-term monitoring sites are presented in Appendix 2.

Antarctic blue whale calls were detected year-round in the monitored area. Nonetheless, they were mostly detected from April to November at the northernmost sites (MAD-W, MAD, MAD-E, RTJ, NEAMS, SSEIR, SWAMS). At WKER and ELAN, the peak acoustic presence 

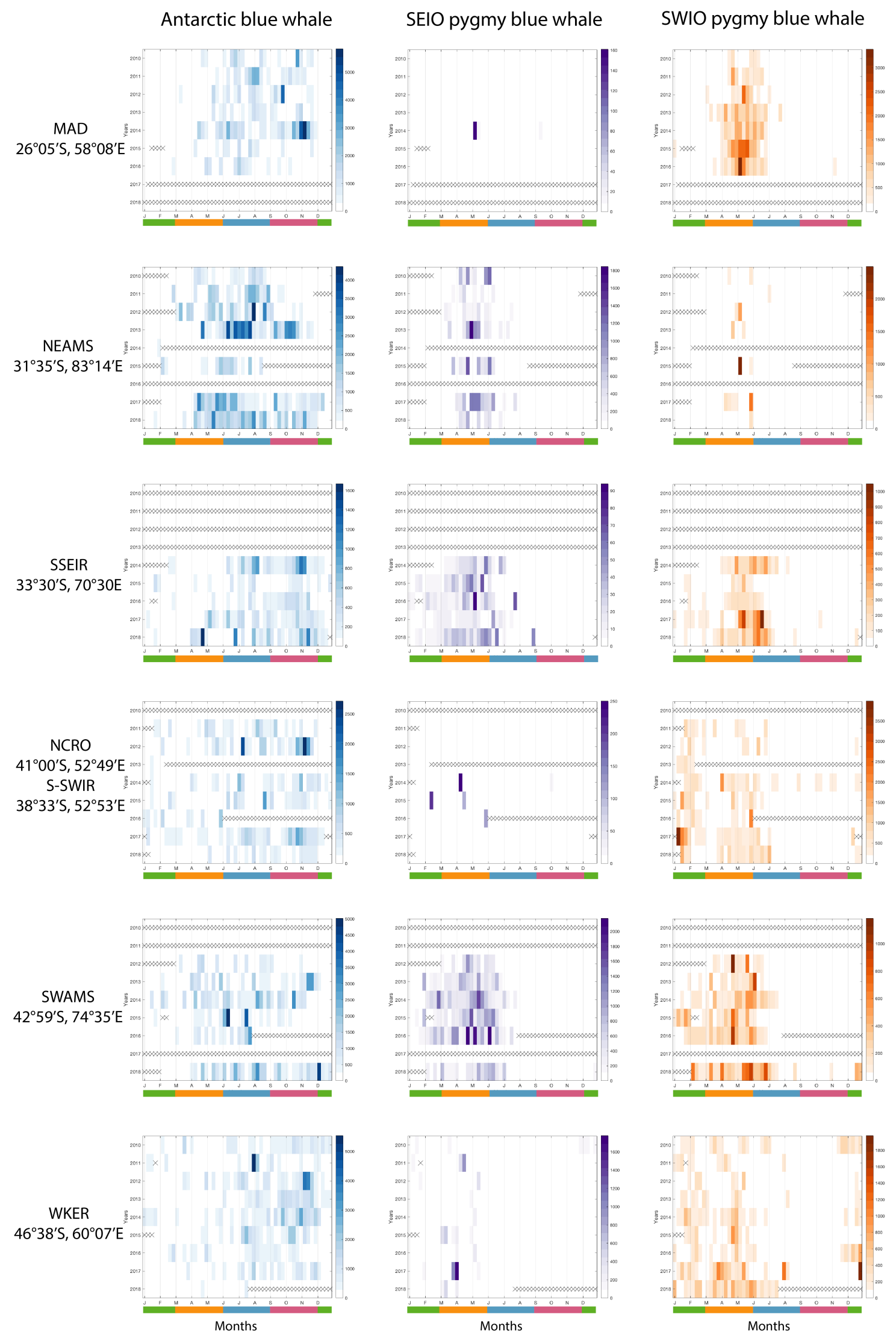

Figure 4: Blue whale weekly acoustic presence. Each row corresponds to a recording site and each column to a blue whale call type. Each graph shows the density of calls per week (color intensity) for every month (x-axis) of the year in the y-axis. Note that the color scale is different for every graph). Weeks with fewer than 6 days of recordings are shown by X. Seasons are shown below the x-axis in different colors (summer: green, autumn: orange, winter: blue, spring: pink). 
Toumal Pre-nron

was shifted and occurred from July until December/January. The seasonality was less clear at S-SWIR and NCRO where the calls were detected almost all year long.

Detection of SEIO pygmy blue whale calls was highly seasonal, from from February until June and peaking in autumn (March and April). They were detected a bit later at NEAMS (from March/April). At WKER, SEIO pygmy blue whale calls were recorded every year, during a few weeks between January and May. At MAD and NCRO, SEIO pygmy blue whale call detections only occurred rarely, during one week in March 2014 at MAD and during a few weeks in April 2014, in February and April 2015 and in May 2016 at NCRO. At the short term sites (RTJ, MAD-E and ELAN), SEIO pygmy blue whale calls were briefly detected, with a few calls spread on a small number of weeks, mostly during May and June.

The presence of SWIO pygmy blue whale calls was also highly seasonal, especially north of the array, where they were mostly detected from March until July (MAD-W). At MAD-E and MAD, the seasonality was even more restrained, occurring only between April and June. At NEAMS, they were only detected during a few weeks per year in April or May. At SSEIR, calls were mostly detected between May and July, with sometimes a few detections from February until April. At NCRO and S-SWIR, the detection pattern seemed bimodal, with calls detected from January to February and then from April until June. At SWAMS, calls could be detected from January to June although occasionally they were detected as early as December. South of the array, SWIO pygmy blue whale calls were sometimes detected as early as mid-November until July at WKER, and from mid-October until January and then from April to July at ELAN.

The inter-annual correlations (Pearson's coefficients) are higher for pygmy blue whale presence than for that of Antarctic blue whales (Table 3). The seasonality of the latter was quite variable, with only a few pairs of years with a high correlation coefficient. Most of the time, the null hypothesis could not be rejected for Antarctic blue whale presence, especially at NCRO where only one pair of years was correlated and SWAMS where no correlation was found. The greatest correlation coefficient (57\%) occurred at WKER, between 2013 and 2014.

Pygmy blue whales followed a more stable presence pattern over the years, particularly at sites with a large number of detections (e.g. SWAMS for SEIO pygmy blue whales and MAD 
Table 3: Pearson correlation coefficients for each pair of years. X means that no data were available and * means that the correlation was not significant and therefore that the null hypothesis could not be rejected $(\mathrm{p}>0.05)$

\begin{tabular}{|c|c|c|c|c|c|c|c|}
\hline & & MAD & NEAMS & SSEIR & NCRO/S-SWIR & SWAMS & WKER \\
\hline \multirow{8}{*}{ Antarctic blue whale } & $2010-2011$ & * & 0.38 & $\mathrm{X}$ & $\mathrm{X}$ & $\mathrm{X}$ & * \\
\hline & 2011-2012 & 0.37 & 0.43 & $\mathrm{X}$ & $*$ & $\mathrm{X}$ & * \\
\hline & 2012-2013 & * & $*$ & $\mathrm{X}$ & * & $*$ & 0.50 \\
\hline & 2013-2014 & 0.28 & * & $\mathrm{X}$ & * & * & 0.57 \\
\hline & 2014-2015 & * & $\mathrm{X}$ & 0.43 & * & * & * \\
\hline & 2015-2016 & 0.29 & $\mathrm{X}$ & 0.40 & * & * & * \\
\hline & 2016-2017 & $\mathrm{X}$ & $\mathrm{X}$ & * & * & $\mathrm{X}$ & * \\
\hline & 2017-2018 & $\mathrm{X}$ & * & * & 0.31 & $\mathrm{X}$ & * \\
\hline \multirow{8}{*}{ SEIO pygmy blue whale } & $2010-2011$ & $\mathrm{X}$ & $*$ & $\mathrm{X}$ & $\mathrm{X}$ & $\mathrm{X}$ & $*$ \\
\hline & 2011-2012 & $\mathrm{X}$ & $*$ & $\mathrm{X}$ & $\mathrm{X}$ & $\mathrm{X}$ & * \\
\hline & 2012-2013 & $\mathrm{X}$ & 0.53 & $\mathrm{X}$ & $\mathrm{X}$ & 0.65 & * \\
\hline & 2013-2014 & $\mathrm{X}$ & * & $\mathrm{X}$ & $\mathrm{X}$ & 0.50 & * \\
\hline & 2014-2015 & $\mathrm{X}$ & $\mathrm{X}$ & 0.40 & * & 0.52 & * \\
\hline & 2015-2016 & $\mathrm{X}$ & $\mathrm{X}$ & 0.41 & * & $*$ & * \\
\hline & 2016-2017 & $\mathrm{X}$ & $\mathrm{X}$ & 0.35 & $\mathrm{X}$ & $\mathrm{X}$ & 0.43 \\
\hline & $2017-2018$ & $\mathrm{X}$ & 0.33 & * & $*$ & $\mathrm{X}$ & * \\
\hline \multirow{8}{*}{ SWIO pygmy blue whale } & $2010-2011$ & 0.78 & $*$ & $\mathrm{X}$ & $\mathrm{X}$ & $\mathrm{X}$ & * \\
\hline & 2011-2012 & 0.49 & * & $\mathrm{X}$ & $*$ & $\mathrm{X}$ & * \\
\hline & 2012-2013 & 0.49 & * & $\mathrm{X}$ & $\mathrm{X}$ & $*$ & * \\
\hline & 2013-2014 & 0.81 & * & $\mathrm{X}$ & $\mathrm{X}$ & 0.56 & 0.56 \\
\hline & 2014-2015 & 0.76 & $\mathrm{X}$ & * & * & 0.31 & 0.68 \\
\hline & 2015-2016 & 0.83 & $\mathrm{X}$ & 0.69 & * & 0.59 & 0.31 \\
\hline & 2016-2017 & $\mathrm{X}$ & $\mathrm{X}$ & 0.57 & * & $\mathrm{X}$ & 0.40 \\
\hline & $2017-2018$ & $\mathrm{X}$ & 0.90 & 0.71 & 0.66 & $\mathrm{X}$ & * \\
\hline
\end{tabular}

for SWIO pygmy blue whales). The correlation was smaller or non-significant at less frequented sites (e.g. WKER and NCRO for SEIO pygmy blue whales and NEAMS for SWIO pygmy blue whales). The only exceptions were at NEAMS, a site with consistent SEIO pygmy blue whale detections, and at NCRO, a site with consistent SWIO pygmy blue whale detections.

\subsection{Sympatry}

Both pygmy and Antarctic blue whale calls occur at most of the OHASISBIO array sites. The western sites are mostly frequented by Antarctic and SWIO pygmy blue whales and the eastern sites by Antarctic blue whales and SEIO pygmy blue whales. The three acoustic populations are commonly recorded at NEAMS, SWAMS and WKER (Figure 3). Figure 4 shows that blue whales acoustic populations sometimes acoustically co-occured. The results of the Spearman's correlation tests are shown in Table 4. For the sites where both pygmy blue whales were recorded (MAD-E, NEAMS, SSEIR, SWAMS and WKER), Spearman's correlations are positive. In other words, when the number of SWIO pygmy blue whale calls increases, the number of SEIO pygmy blue whale calls increases as well. The only exception is at ELAN, where the correlation is not significant. On the contrary, Antarctic blue whale seasonal presence 
is generally negatively correlated with the pygmy blue whale presence. Therefore, except at

MAD and NEAMS, their acoustic presence does not match that of the pygmy blue whales.

Table 4: Spearman correlation coefficient by pair of populations. For a given site, a positive value means the two considered populations are jointly present, a negative value means that they are not present at the same times, an X means a lack of calls for one or both populations, and an asterisk $\left(^{*}\right)$ means that the correlation was not significant (i.e. the null hypothesis could not be rejected $(\mathrm{p}>0.05))$.

\begin{tabular}{|c|c|c|c|c|c|c|c|c|c|}
\hline & ELAN & MAD & MAD-E & MAD-W & NEAMS & SSEIR & NCRO/S-SWIR & SWAMS & WKER \\
\hline SEIO - SWIO populations & $*$ & $\mathrm{X}$ & 0.49 & $\mathrm{X}$ & 0.30 & 0.65 & $\mathrm{X}$ & 0.77 & 0.51 \\
\hline Antarctic - SWIO populations & * & 0.11 & -0.34 & * & 0.17 & -0.24 & -0.21 & $*$ & -0.33 \\
\hline Antarctic - SEIO populations & $*$ & $\mathrm{X}$ & -0.37 & $\mathrm{X}$ & 0.40 & -0.40 & $\mathrm{X}$ & $*$ & -0.23 \\
\hline
\end{tabular}

For the sites where both pygmy blue whales were recorded (MAD-E, NEAMS, SSEIR, SWAMS and WKER), there was a positive monotonical correlation. In other words, when the number of SWIO pygmy blue whale calls increase, the number of SEIO pygmy blue whale calls tend to increase as well. The only exception is at ELAN, where the correlation is not significant. On the contrary, Antarctic blue whale seasonal presence often negatively correlated with the pygmy blue whale presence. Therefore, their acoustic presence is offset from that of the pygmy blue whale call types.

Figure 5 shows the number of hours with acoustic co-occurence either from both pygmy blue whales or from Antarctic blue whales and one pygmy blue whale population. We only show sites with at least $5 \%$ of hours with sympatry within any month of the year. For pygmy blue whales (Figure 5a), the only site that meets this condition is SWAMS, with peak co-occurence from March to June. For Antarctic and pygmy blue co-occurence (Figure 5), MAD-W is the site with the greatest co-occurence, with $40 \%$ of hours in June. Other sites with acoustic sympatry include MAD, NCRO, NEAMS and SWAMS. The main period of co-occurence is between April and June except at NCRO, where greatest co-occurence happens in January.

\section{Discussion}

\subsection{Using passive acoustics to monitor blue whale populations}

Passive acoustic monitoring with a wide network of hydrophones is a very effective approach to detect the presence of blue whales, as in this study. However it cannot be used to determine the 

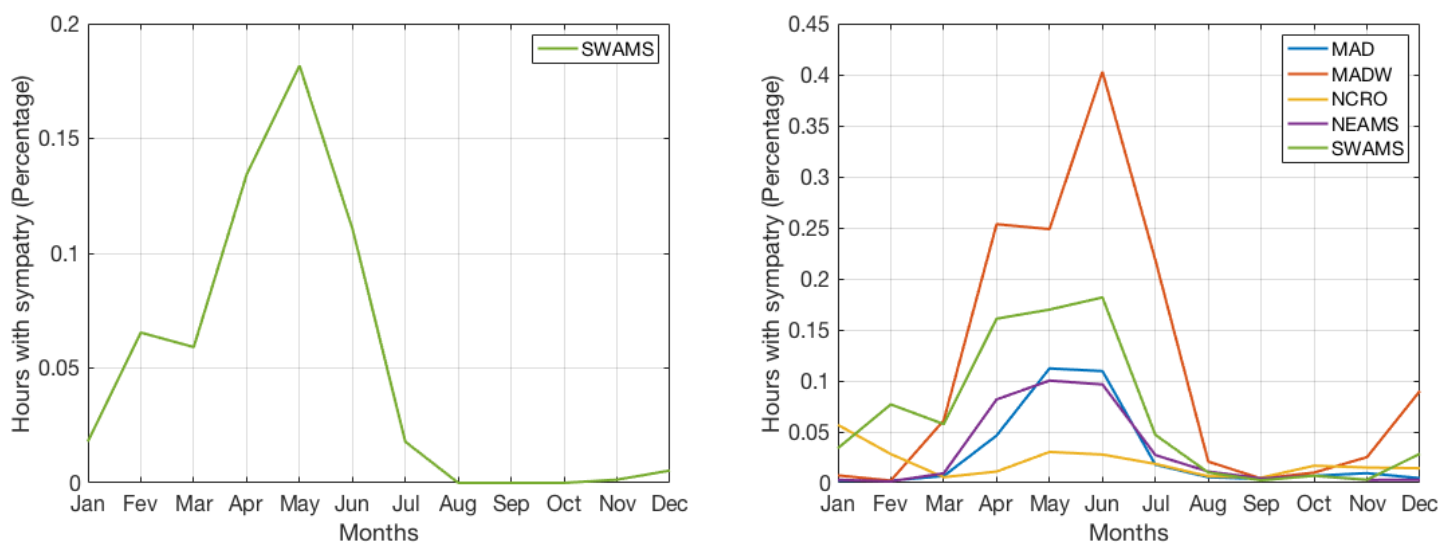

Figure 5: Number of hours per month with sympatric detections of blue whale calls a) SEIO and SWIO pygmy blue whales b) Antarctic blue whales and SEIO or SWIO pygmy blue whales. The number of detections is normalized by the number of hours of recording available for each month, over the total duration of the recordings (from 2010 to 2018)

abundance of whales in the vicinity of an hydrophone based on the number of detected calls. Indeed, several factors can influence the number of blue whale calls present in the data. Some of them are dependent on blue whale behavior (e.g. when, where and why they sing and how song structure changes) and others are dependent on sound propagation dynamics that affect the detection ranges of calls.

For instance, a recent study found that the structure of SEIO pygmy blue whale songs shows variations (Joliffe et al., 2019). The usual 3-unit song was sometimes shortened by whales omitting one of the units. If the omitted unit is the one targeted by a detector, then the relationship between the number of call detections and the density of whales in the vicinity of the hydrophone may change. This phenomenon has not been studied in other blue whale populations. In the OHASISBIO data, it is rare to observe the full 3-unit SEIO pygmy blue whale vocalisation (due to loud background noise and and only the loudest unit is used for the automated detection (see Figure 1). Variations in song structure are therefore less straightforward to observe, but they may explain some of the inter-annual variations in the number of detections.

Acoustic detection ranges of blue whales are way larger than visual observation ranges. The estimated detection range for Antarctic blue whale calls is about $200 \mathrm{~km}$ (Širović et al., 2007. Samaran et al., 2010b; Thomisch et al., 2016). Pygmy blue whale call detection range is not well known. There is a tradeoff in that the lower background noise in the higher frequencies used 
Joumal Pre-proof

by pygmy blue whales suggests that their vocalisations could propagate further than Antarctic blue whale ones. However, higher pitched sounds tend to propagate less far and it seems that pygmy blue whale calls have lower source levels than Antarctic blue whale calls (Samaran et al. 2010b). Therefore, their detection range is probably smaller than $200 \mathrm{~km}$ (Samaran et al. 2010a). Moreover, variability in the annual or seasonal number of calls can arise from seasonal changes in the sound propagation range. This range relies on many environmental parameters (e.g. the sound speed, the bathymetry and the background noise) that can evolve over time. For example, Thomisch et al. (2019) found that depending on the season, the propagation range of blue whale calls can vary from $200 \mathrm{~km}$ to $500 \mathrm{~km}$. A greater propagation range increases the hydrophone detection area. This may result in an increase in the number of call detections that is not reflective of a true increase in blue whale numbers in the vicinity of the hydrophone. Computing seasonal detection range variations for our many sites is beyond the scope of this paper. However we assume that our detection patterns are representative of a regional blue whale presence around the hydrophones rather than a very local one.

\subsection{Spatial distribution of blue whale populations in the southwest Indian Ocean}

Ovarian data collected from 1934 to 1972 suggested that $60^{\circ} \mathrm{S}$ was the northern limit of Antarctic blue whale distribution (Branch et al., 2009). However, since 2010, acoustic surveys have demonstrated that Antarctic blue whales regularly occur in subantarctic and subtropical latitudes of the Indian Ocean (Stafford et al., 2004, Samaran et al., 2010a, 2013, Leroy et al., 2016), the Pacific Ocean (Stafford et al., 1999, 2004, Buchan et al., 2018) and even in the equatorial Atlantic Ocean (Samaran et al., 2019). Overall, the Antarctic blue whale acoustic presence results presented here match those reported in Leroy et al. (2016) for MAD, SSEIR, NEAMS, SWAMS, NCRO and WKER sites from 2010 to 2015. A large number of calls detected annually at the additional sites included here confirms the importance of the subtropical and southern Indian Ocean for this sub-species. The most consistently visited site by Antarctic blue whales seems to be MAD-W, suggesting either that this region concentrates many individuals or that their calling rate is higher in this vicinity. Sites MAD-E and RTJ seem less occupied, implying 
Joumal Pre-proot

that they may define the northern limits of their distribution in the Indian Ocean. No Antarctic blue whale calls were recorded at RAMA, but only two years of data were available for this site, so it may occasionally be frequented by Antarctic blue whales. For now, the northern limit of their distribution in the Indian Ocean is thus thought to be located around the Diego Garcia archipelago, $7.6^{\circ} \mathrm{S}$ (Stafford et al., 2004). The longer time series confirms the observation of Leroy et al. (2016) that SSEIR, NCRO and and its neighboring S-SWIR site are less used by vocal Antarctic blue whales than the other sites. These regions could be suboptimal for Antarctic blue whales or their call rate is lower there for an unknown reason. This is the first time that Antarctic blue whale acoustic presence is reported at ELAN, the southernmost hydrophone site. It provides additional evidence of Antarctic blue whale presence around the entire Southern Ocean (Širović et al., 2004, 2009, Gedamke and Robinson, 2010, Miller et al. 2015; Thomisch et al., 2016).

SEIO pygmy blue whale calls have been previously recorded off southern (Gill, 2002, Gavrilov et al. 2011) and western Australia (McCauley et al., 2000, 2018, Stafford et al., 2011; Balcazar et al. 2015). The eastern limit of their distribution is the Bass strait (Balcazar et al., 2015, McCauley et al. 2018) with the exception of a few extralimital detections near the Juan Fernandez Islands in the SE Pacific Ocean (Buchan et al., 2020). Satellite telemetry has revealed SEIO pygmy blue whale distribution along the western Australian coast as far north as Indonesian waters (Double et al., 2014). In the eastern part of the Indian Ocean, SEIO pygmy blue whale calls were recorded as far west as the Crozet archipelago (Samaran et al., 2010a). Our results support the broad scale study in Leroy et al. (2018b) where a strong chorus is observed at 70 $\mathrm{Hz}$ at the easternmost sites, SWAMS, SSEIR and to a lesser extent at NEAMS. SEIO pygmy blue whale calls are consistently recorded at SWAMS, NEAMS and less so at WKER. Even fewer calls are detected at SSEIR, suggesting that SEIO pygmy blue whales are uncommon at SSEIR. Therefore, the western limit of their general distribution could be located between the sites ELAN/WKER/SSEIR and NEAMS/SWAMS. SEIO pygmy blue whales clearly range far from the west coast of Australia based on the data presented here and in previous studies (Samaran et al., 2010a; Stafford et al., 2011; Samaran et al., 2013; Leroy et al., 2018b). Like for most pygmy blue whale populations globally, breeding grounds are largely unknown. However, SEIO pygmy blue whale calls were neither detected at Diego Garcia Stafford et al. (2011), nor 
at RAMA. If the calls are only a mating display it would be unlikely that the northern Indian

Ocean is a breeding ground for this population.

Recent analysis using the Chorus to Noise Ratio (CNR) metric revealed that SWIO pygmy blue whale population is distributed at least from $26^{\circ} \mathrm{S}$ (Leroy et al., 2018b; Dréo et al., 2018) to $46^{\circ} \mathrm{S}$ and $52^{\circ} \mathrm{E}$ to $74^{\circ} \mathrm{E}$. Overall, it is clear that SWIO pygmy blue whale acoustic presence is stronger in the western Indian Ocean (sites MAD, MAD-W, NCRO) and diminishes when going to the east towards SSEIR and SWAMS sites. The eastern boundary of their distribution may be located at the eastern limit of our hydrophone array, as suggested by Leroy et al. (2016). To the north, a few SWIO pygmy blue whale calls were detected at NEAMS and Diego Garcia (Stafford et al., 2011), which could be the northern limit of SWIO pygmy blue whale distribution. Only chorus was detected at RTJ. Longer time series at RTJ and Diego Garcia could refine the northern limit of this pygmy blue whale population distribution. Consistent detection of SWIO pygmy blue whale calls at WKER and also on the single year of data at ELAN, confirms that they also occupy the subantarctic Indian Ocean as previously observed by (Gedamke and Robinson, 2010).

\subsection{Seasonal distribution of blue whale populations in the southwest Indian Ocean}

The analysis of the first years of the OHASISBIO recordings demonstrated that Antarctic blue whale acoustic distribution is seasonal in the southwest Indian Ocean (Samaran et al., 2010a, 2013; Leroy et al., 2016, 2018b). The monthly seasonal pattern is stable over the years but differs among sites, with more detections during autumn and spring (March to May and September to November) at the subantarctic locations and more detections during winter (June to August) at subtropical locations, suggesting the presence of migration routes and of a wintering, possibly breeding, area at northern latitudes (Leroy et al. 2016). Our observations confirm these findings at a finer and longer temporal scale (Figure 4 and Table 3). Generally, the peak of detections occurs during the second part of the year (from March to December) at most of the sites, including the southernmost subantarctic site ELAN. This is complementary to the seasonal acoustic presence recorded in Antarctica (Širović et al., 2004, 2009, Thomisch et al., 2016), 
where the peak occurs during the first trimester of the year (January until March/April). This suggests a migration pattern from southern latitudes where they are heard from December to April to lower latitudes from April to November. However, acoustic presence nearly all year round at some subantarctic and subtropical locations (WKER, NCRO and SWAMS) is indicative of some animals not migrating every year (Thomisch et al., 2019).

This year-round acoustic presence is not observed for pygmy blue whales in the array and more broadly, in the Indian Ocean basin. To the west, SEIO pygmy blue whale calls are recorded as far east as the Crozet Archipelago in May and June. In the southwest Indian Ocean, their calls are recorded consistently, with a clear seasonal pattern from February until June, and no detections from July to January. Our results confirm that SEIO pygmy blue whale acoustic presence is highly seasonal in the Indian Ocean, between February and June at SSEIR and SWAMS and from April to June at NEAMS. SEIO pygmy blue whale calls were absent from our recordings from August through December. It is not clear yet whether they stop singing or dwell in a different area during this period, perhaps Indonesian waters, where their presence was revealed by satellite telemetry from July to September (Double et al., 2014).

Our results support the previous findings that SWIO pygmy blue whale acoustic presence is highly seasonal (April and/or May) in the northwest of the hydrophone array. They also provide more accurate information on the acoustic presence of SWIO pygmy blue whales further south. SWIO pygmy blue whale calls were detected from November until June or July at WKER and mostly from October until December at ELAN. Their presence at NCRO is bimodal with two peaks, the first from December to February and second from April to June. Similar detection patterns are reported north of the Mozambique channel (from May to July and from November to January) (Cerchio et al., 2018) and implies a possible double migration pattern. A first migration would occur from high latitudes (ELAN, WKER) in summer (December to February) to low latitudes in autumn or winter (MAD-W, MAD) then back again to higher latitudes in the middle of winter (June to August). The absence of call detections during austral spring (from August to October) might indicate a change in SWIO pygmy blue whale vocal behavior or a migratory corridor different from the one they use in autumn to go from south to north, for example along the eastern coast of South Africa (Branch et al., 2007). The second migration pattern would involve a migratory corridor located north of the Mozambique channel 
Joumal Pre-proof

and frequented twice a year (from May to July and from November to January) (Cerchio et al.

2018). The absence of call from August until October both in the Mozambique channel (Cerchio et al. 2018), and in the OHASISBIO array suggest a migration in the northern Indian Ocean. However, there is no evidence of their presence in the north of the Indian Ocean during this period.

\subsection{Long term and seasonal variability}

Long-term monitoring of Antarctic blue whale acoustic presence did not reveal global trends in the number of calls recorded annually over time despite clear seasonal variations in number of detections. It is possible that some areas are more appealing to whales in certain years and attract more individuals than the previous years at the expense of other areas. However, Antarctic blue whale calls were detected every year at all sites, suggesting that they do not all abandon their wintering ground, even if the environmental conditions may not be optimal. Baleen whales were long thought to fast during migrations and at breeding grounds, nevertheless, the choice of wintering ground for blue whales appears driven by the presence of krill (Branch et al., 2007). Low, or absence of, significant correlation between the weekly presence on two consecutive years emphasizes that Antarctic and pygmy blue whale movements likely rely primarily on environmental conditions. The obvious next step is to examine environmental variability during the same decade (via satellite derived data for sea surface temperature, chlorophyll A, upwelling index) to determine how the physical environment might drive changes in blue whale site frequentation in the array.

Like Antarctic blue whales, the annual numbers of SEIO pygmy blue whale call detections do not display a global trend in the array, but show inter-annual variations. However, the high correlation between weekly presence over two consecutive years at SWAMS suggests a stable seasonal presence. In the Bass Strait, the annual difference of blue whale call detections was hypothesized to be due to fluctuations in the seasonal occurence of krill (Tripovich et al., 2015). McCauley et al. (2018) report a $4.3 \%$ growth rate for the population visiting the Bass Strait, computed from acoustic analysis of call rates. However, they emphasize that this value applies only to the proportion of the SEIO pygmy blue whale population that occupies this region and 
SWIO pygmy blue whale calls are the only ones to show an increasing trend throughout the extent of their distribution in the array. This trend is also visible in the chorus (Leroy et al. 2018b), which could suggest a global population growth (McCauley et al., 2018). However, it is impossible to quantify the extent of this growth solely from acoustic data. The NCRO and SSEIR sites do not display similar tendencies. SWIO pygmy blue whale presence here might be more reliant on environmental drivers than elsewhere as suggested for SEIO pygmy blue whales (Tripovich et al., 2015, Garcia-Rojas et al., 2018). SWIO pygmy blue whale seasonal acoustic presence is very stable at MAD, suggesting that they might come here every year, no matter the changing environmental conditions. These observations might indicate that $\mathrm{NCRO}$ and SSEIR regions are feeding areas en route to the Madagascar basin, around the site MAD.

\subsection{Use of the southern Indian Ocean by multiple blue whale pop- ulations}

Antarctic blue whale calls are present year-round in the southern Indian Ocean, but with peaks during winter and spring (from June to November) whereas SWIO and SEIO pygmy blue whales are heard seasonally mostly during summer, autumn and early winter (from January to June). The negative correlation between Antarctic and pygmy blue whale seasonal presence confirms the complementary use of the Indian Ocean by the two subspecies. Moreover, each seems to have different migratory strategies. Antarctic blue whales may not all migrate south annually as indicated by their year-round presence at sub-antarctic locations (Leroy et al., 2016; Thomisch et al., 2019). In contrast, highly seasonal acoustic presence and absence indicates a clear migration pattern for pygmy blue whales. Such differences in geographic and seasonal occupancy of the southern Indian Ocean by Antarctic and pygmy blue whales could reflect prey preference, different habitat use (i.e. breeding or feeding), but also very different life history strategies between a highly mobile sub-species (Antarctic blue whales) and a sub-species that is largely resident to the Indian Ocean (pygmy blue whales).

Productive Antarctic waters are the main Antarctic blue whale feeding grounds. This subspecies feeds mainly on large Antarctic krill (Euphausia superba) (Kawamura, 1980; Miller et al. 
Journal Pre-proo

2019). Antarctic blue whale migration is guided by the seasonal presence of krill in summer in high latitudes. Presumably, a part of the population remains year-round at lower latitudes (Thomisch et al. 2019).

Such a partial migration to the Antarctic feeding ground may be driven by the year-round availability of prey in the subantarctic and subtropical Indian Ocean. The SEIO pygmy blue whale population has been observed feeding on Nyctiphanes australis south of Australia during autumn (Gill, 2002). SWIO pygmy blue whale feeding grounds are not precisely known, but stomach contents showed that around Crozet and Kerguelen islands they ate mainly Euphausia frigida and E. vallentini (Nemoto, 1962). Their diet seems to shift in South African waters to E. recurva or E. diomedeae (Kawamura, 1980). These differences in diet might be due to geographic availability of prey.

SWAMS is the site with the greatest number of calls from the three acoustic populations studied here. Co-occurence of Antarctic and SWIO pygmy blue whales happens mostly at the western sites (MAD, MAD-E, MAD-W, NCRO) whereas co-occurence of Antarctic blue whales and SEIO pygmy blue whales mostly occurs to the east (SWAMS, NEAMS) (Figure 5). Hourly acoustic co-occurence does not necessarily mean that the vocalizing whales could hear each other, as one could be located at one limit of the hydrophone detection range and another one at the opposite limit, for instance. However, it indicates that a relatively small area was occupied by two different blue whale acoustic populations. It is therefore an indicator of a region of high interest for blue whales. Assuming that SEIO and SWIO pygmy blue whales both breed during winter, they might all use the northern Indian Ocean as a common breeding ground with Antarctic blue whales. Attard et al. (2012) reported a case of hybridation between an Antarctic blue whale and a pygmy blue whale from a whale biopsied off Antarctica. The acoustic co-occurrence during late autumn and beginning of winter (April to June) in the northern Indian Ocean could indicate potential co-breeding grounds. MAD-W could be a candidate breeding ground for both Antarctic blue whales and SWIO pygmy blue whales, and NEAMS for both Antarctic blue whales and SEIO pygmy blue whales. Neither pygmy blue whale population appears to co-occur at any northern site of the array (MAD, NEAMS), suggesting that they might have separate breeding grounds. However, sympatry of feeding SEIO pygmy blue whales and migrating or breeding Antarctic blue whales during autumn (March 
to May) south of Australia (Tripovich et al., 2015) suggest that acoustic co-occurence might also indicate regions used for two different purposes by different acoustic populations of blue whales. Clearly, while passive acoustic monitoring has provided unprecedented information about the seasonal and geographic occurrence of multiple acoustic populations of blue whales in the southern Indian Ocean, it is only through interdisciplinary studies that include visual observations, that we will fully understand the ecology of Indian Ocean blue whales.

\section{Conclusion}

This study documents the presence of three blue whale acoustic populations for nearly a decade in the southern Indian Ocean. Its results are based on a long and continuous time series and on the application of a single algorithm for the detection of the different calls. These results support the spatial and seasonal distribution previously depicted in this region and the additional years and recording locations refine these previous findings, both temporally and geographically. What is immediately clear from the data is that Antarctic and pygmy blue whales use the southern Indian Ocean very differently. The former is acoustically recorded almost year-round whereas the latter are recorded only seasonally. Moreover, Antarctic blue whale migration is highly variable from one year to the next while pygmy blue whale seasonality appears relatively stable. Antarctic and pygmy blue whales co-occur, especially in the north of the OHASISBIO array. SEIO and SWIO pygmy blue whales have a similar seasonality in the southern Indian Ocean, but their distribution only overlaps slightly around SWAMS, where they mostly co-occur mostly from April to June.

The next steps to better understand how blue whales use the southern Indian Ocean are multiple. First, additional recording locations could be established, especially along the eastern African coast for SWIO pygmy blue whales and between the OHASISBIO hydrophone array and Australia for SEIO pygmy blue whales. This would refine the limit of distribution and perhaps complete our knowledge about pygmy blue whale migration routes. Second, for all subspecies, additional behavioral information is needed to better understand in which context they produce calls. Finally, comparing seasonal presence, behavior and environmental data would be useful to define preferential Antarctic and pygmy blue whale habitats in the southern 


\section{Acknowledgments}

The authors wish to thank the captains and crews of RV Marion Dufresne for the successful deployments and recoveries of the instruments of the OHASISBIO array. Cruises were funded by the French Polar Institute and and the French Oceanographic Fleet, with additional support from INSU-CNRS. M.T. was supported by a Ph.D. fellowship from the University of Brest. Her visit to K.M.S. was supported by a grant from the ISblue project, Interdisciplinary graduate school for a blue planet (ANR-17-EURE-0015), a project of the French Government program "Investissements d'Avenir'. The authors thank Angélique Drémeau for her precious advice on statistical analysis. The contribution of Mickaël Beauverger at LGO in the preparation and realization of the cruise is greatly appreciated. Finally, the authors would like to acknowledge the two anonymous reviewers for their precious comments that greatly helped to improve this paper.

\section{References}

Attard, C. R. M., Beheregaray, L. B., Jenner, K. C. S., Gill, P. C., Jenner, M.-n., and Morrice, M. G. (2012). Hybridization of southern Hemisphere blue whale subspecies and a sympatric area off Antarctica : impacts of whaling or climate change ? Molecular Ecology, 21:57155727.

Balcazar, N. E., Tripovich, J. S., Klinck, H., Nieukirk, S. L., Mellinger, D. K., Dziak, R. P., and Rogers, T. L. (2015). Calls reveal population structure of blue whales across the Southeast Indian Ocean and the Southwest Pacific Ocean. Journal of Mammalogy, 96(6):1184-1193.

Branch, T. A., Mikhalev, Y. A., and Kato, H. (2009). Separating pygmy and Antarctic blue whales using long-forgotten ovarian data. Marine Mammal Science, 25(October):833-854.

Branch, T. A., Stafford, K. M., Palacios, D. M., Allison, C., Bannister, J. L., Burton, C., Cabrera, E., Carlson, C. A., Galletti Vernazzani, B., Gill, P. C., Hucke-Gaete, R., Jenner, K. 
C. S., Jenner, M. N., Matsuoka, K., Mikhalev, Y. A., Miyashita, T., Morrice, M. G., Nishiwaki, S., Sturrock, V. J., Tormosov, D., Anderson, R. C., Baker, A. N., Best, P. B., Borsa, P., Brownell, R. L., Childerhouse, S., Findlay, K. P., Gerrodette, T., Ilangakoon, A. D., Joergensen, M., Kahn, B., Ljungblad, D. K., Maughan, B., McCauley, R. D., McKay, S., Norris, T. F., Rankin, S., Samaran, F., Thiele, D., Van Waerebeek, K., and Warneke, R. M. (2007). Past and present distribution, densities and movements of blue whales (Balaenoptera musculus in the Southern Hemisphere and northern Indian Ocean. Mammal Review, 37(2):116-175.

Buchan, S. J., Balcazar-Cabrera, N., and Stafford, K. M. (2020). Seasonal acoustic presence of blue, fin, and minke whales off the juan fernández archipelago, chile (2007-2016). Marine Biodiversity, 50(5):1-10.

Buchan, S. J., Hucke-Gaete, R., Stafford, K. M., and Clark, C. W. (2018). Occasional acoustic presence of Antarctic blue whales on a feeding ground in southern Chile. Marine Mammal Science, 34(January):220-228.

Cerchio, S., Rasoloarijao, T., and Cholewiak, D. M. (2018). Acoustic monitoring of blue whales (Balaenoptera musculus) and other baleen whales in the Mozambique Channel off the northwest coast of Madagascar (SC/67B/SH/14). Technical report, International Whaling Commission.

Clark, C. W. and Ellison, W. T. (2004). Potential use of low-frequency sounds by baleen whales for probing the environment: evidence from models and empirical measurements. Echolocation in bats and dolphins, pages 564-582.

Cooke, J. (2019). Balaenoptera musculus, (errata version published in 2019). Technical report, The IUCN Red List of Threatened Species 2018.

Cummings, W. C. and Thompson, P. O. (1971). Underwater sounds from the blue whale, Balaenoptera musculus. The Journal of the Acoustical Society of America, 50(4B):1193.

d'Eu, J.-F., Royer, J.-Y., and Perrot, J. (2012). Long-term autonomous hydrophones for largescale hydroacoustic monitoring of the oceans. In 2012 Oceans-Yeosu, pages 1-6. IEEE.

Double, M. C., Andrews-Goff, V., Jenner, K. C. S., Jenner, M. N., Laverick, S. M., Branch, T. A., and Gales, N. J. (2014). Migratory movements of pygmy blue whales (Balaenoptera 
musculus brevicauda) between Australia and Indonesia as revealed by satellite telemetry. PLoS ONE, 9(4):1-11.

Dréo, R., Bouffaut, L., Leroy, E. C., Barruol, G., and Samaran, F. (2018). Baleen whale distribution and seasonal occurrence revealed by an ocean bottom seismometer network in the Western Indian Ocean. Deep-Sea Research Part II: Topical Studies in Oceanography.

Garcia-Rojas, M. I., Jenner, K. C. S., Gill, P. C., Jenner, M. N. M., Sutton, A. L., and Mccauley, R. D. (2018). Environmental evidence for a pygmy blue whale aggregation area in the Subtropical Convergence Zone south of Australia. Marine Mammal Science, pages 1-23.

Gavrilov, A. N., McCauley, R. D., and Gedamke, J. (2012). Steady inter and intra-annual decrease in the vocalization frequency of Antarctic blue whales. The Journal of the Acoustical Society of America, 131(6):4476-4480.

Gavrilov, A. N., McCauley, R. D., Salgado-Kent, C., Tripovich, J. S., and Burton, C. (2011). Vocal characteristics of pygmy blue whales and their change over time. The Journal of the Acoustical Society of America, 130(6):3651-3660.

Gedamke, J. and Robinson, S. M. (2010). Acoustic survey for marine mammal occurrence and distribution off East Antarctica $\left(30-80^{\circ} \mathrm{E}\right)$ in January-February 2006. Deep-Sea Research Part II, 57(9-10):968-981.

Gill, P. C. (2002). A blue whale (Balaenoptera musculus) feeding ground in a southern australian coastal upwelling zone. Journal of Cetacean Research and Management, 4(2):179-184.

Guilment, T., Socheleau, F.-X., Pastor, D., and Vallez, S. (2018). Sparse representationbased classification of mysticete calls. The Journal of the Acoustical Society of America, 144(3):1550-1563.

Harmer, S. F. (1931). Southern whaling. In Proc. Linn. Soc. Lon., volume 142, pages 85-163.

Ichihara, T. (1966). The pygmy blue whale, balaenoptera musculus brevicauda, a new subspecies from the antarctic. Whales, dolphins, and porpoises, pages 79-111.

IWC (1980). Chairman's report of the thirty-first annual meeting. Rep. int. Whal. Commn, $30: 25-41$. 
Joumal Pre-proof

Joliffe, C. D., McCauley, R. D., Gavrilov, A. N., Jenner, K. C. S., Jenner, M.-N. M., and Duncan, A. J. (2019). Song variation of the South Eastern Indian Ocean pygmy blue whale population in the Perth Canyon, Western Australia. PLoS ONE, pages 1-26.

Kawamura, A. (1980). A review of food of balaenopterid whales. Sci. Rep. Whales Res. Inst, 32:155-197.

Kellogg, R. (1929). What is known of the migrations of some of the whalebone whales. US Government Printing Office.

LeDuc, R., a.G. Dizon, Goto, M., Pastene, L., Kato, H., Nishiwaki, C., LeDuc, C., and Brownell, R. (2007). Patterns of genetic variation in Southern Hemisphere blue whales and the use of assignment test to detect mixing on the feeding grounds. J. Cetacean Res. Manage, 9:73-80.

Leroy, E. C., Royer, J.-Y., Bonnel, J., and Samaran, F. (2018a). Long-term and seasonal changes of large whale call frequency in the Southern Indian Ocean. Journal of Geophysical Research: Oceans, 123:1-13.

Leroy, E. C., Samaran, F., Bonnel, J., and Royer, J.-Y. (2016). Seasonal and diel vocalization patterns of Antarctic blue whale (Balaenoptera musculus intermedia) in the Southern Indian Ocean: A multi-year and multi-site study. PLoS ONE, 11(11).

Leroy, E. C., Samaran, F., Stafford, K. M., Bonnel, J., and Royer, J.-y. (2018b). Broad-scale study of the seasonal and geographic occurrence of blue and fin whales in the Southern Indian Ocean. Endangered Species Research, 37:289-300.

Lewis, L. A., Calambokidis, J., Stimpert, A. K., Fahlbusch, J., Friedlaender, A. S., McKenna, M. F., Mesnick, S. L., Oleson, E. M., Southall, B. L., Szesciorka, A. R., and Širović, A. (2018). Context-dependent variability in blue whale acoustic behaviour. Royal Society Open Science, 5(8):180241.

Ljungblad, D., Clark, C. W., and Shimada, H. (1998). Sc/49/sh17 a comparison of sounds attributed to pygmy blue whales (balaenoptera musculus brevicauda) recorded south of the madagascar plateau and those attributed to'true'blue whales (balaenoptera musculus) recorded off antarctica. Report-International Whaling Commission, 48:439-442. 
Lurton, X. (2002). An introduction to underwater acoustics: principles and applications. Springer Science \& Business Media.

Mackintosh, N. (1966). The distribution of southern blue and fin whales. Whales, dolphins, and porpoises, pages 125-144.

Mackintosh, N. A. (1942). The southern stocks of whalebone whales. Discovery Rep., 22:197300.

McCauley, R. D., Gavrilov, A. N., Jolli, C. D., Ward, R., and Gill, P. C. (2018). Pygmy blue and Antarctic blue whale presence, distribution and population parameters in southern Australia based on passive acoustics. Deep-Sea Research Part II, 158(October 2017):154-168.

McCauley, R. D., Jenner, C., Bannister, J. L., Cato, D. H., and Duncan, A. (2000). Blue whale calling in the Rottnest trench, Western Australia, and low frequency sea noise. Austral. Acoust. Soc. Conf., 1993(November):1-6.

McDonald, M. A., Calambokidis, J., Teranishi, A. M., and Hildebrand, J. A. (2001). The acoustic calls of blue whales off California with gender data. The Journal of the Acoustical Society of America, 109(4):1728-1735.

McDonald, M. A., Mesnick, S. L., and Hildebrand, J. A. (2006). Biogeographic characterisation of blue whale song worldwide: using song to identify populations. Journal of Cetacean Research and Management, 8(1):55-65.

Miller, B. S., Barlow, J., Calderan, S., Collins, K., Leaper, R., Olson, P., Ensor, P., Peel, D., Donnelly, D., Andrews-Goff, V., et al. (2015). Validating the reliability of passive acoustic localisation: a novel method for encountering rare and remote antarctic blue whales. Endangered Species Research, 26(3):257-269.

Miller, E. J., Potts, J. M., Cox, M. J., Miller, B. S., Calderan, S., Leaper, R., and Olson, P. A. (2019). The characteristics of krill swarms in relation to aggregating Antarctic blue whales. Scientific Reports, pages 1-13.

Nemoto, T. (1962). Food of baleen whales collected in recent japanese antarctic whaling expeditions. Sci. Rep. Whales Res. Inst, 16:89-103. 
Oleson, E. M., Calambokidis, J., Burgess, W. C., McDonald, M. A., Leduc, C. A., and Hildebrand, J. A. (2007). Behavioral context of call production by eastern North Pacific blue whales. Marine Ecology Progress Series, 330(January):269-284.

Royer, J.-Y. (2009). OHASISBIO - Hydroacoustic observatory for the seismicity and biodiversityin the Indian Ocean. Technical report, Université de Bretagne Occidentale.

Samaran, F., Adam, O., and Guinet, C. (2010a). Discovery of a mid-latitude sympatric area for two Southern Hemisphere blue whale subspecies. Endangered Species Research, 12(2):157165.

Samaran, F., Berne, A., Leroy, E. C., Moreira, S., Stafford, K. M., Maia, M., and Royer, J.-Y. (2019). Antarctic blue whales (Balaenoptera musculus intermedia) recorded at the Equator in the Atlantic Ocean. Marine Mammal Science, 35(2):641-648.

Samaran, F., Guinet, C., Adam, O., Motsch, J.-F., and Cansi, Y. (2010b). Source level estimation of two blue whale subspecies in southwestern Indian Ocean. The Journal of the Acoustical Society of America, 127(6):3800-3808.

Samaran, F., Stafford, K. M., Branch, T. A., Gedamke, J., Royer, J.-Y., Dziak, R. P., and Guinet, C. (2013). Seasonal and geographic variation of southern blue whale subspecies in the Indian Ocean. PLoS ONE, 8(8).

Shaw, A. K. and Levin, S. A. (2011). To breed or not to breed: a model of partial migration. Oikos, 120(12):1871-1879.

Širović, A., Bassett, H. R., Johnson, S. C., Wiggins, S. M., and Hildebrand, J. A. (2014). Bryde's whale calls recorded in the Gulf of Mexico. Marine Mammal Science, 30(1):399-409.

Širović, A., Hildebrand, J. A., and Wiggins, S. M. (2007). Blue and fin whale call source levels and propagation range in the Southern Ocean. The Journal of the Acoustical Society of America, 122(2):1208-1215.

Širović, A., Hildebrand, J. A., Wiggins, S. M., McDonald, M. A., Moore, S. E., and Thiele, D. (2004). Seasonality of blue and fin whale calls and the influence of sea ice in the Western 
Antarctic Peninsula. Deep-Sea Research Part II: Topical Studies in Oceanography, 51(1719):2327-2344.

Širović, A., Hildebrand, J. A., Wiggins, S. M., and Thiele, D. (2009). Blue and fin whale acoustic presence around Antarctica during 2003 and 2004. Marine Mammal Science, 25(January):125-136.

Socheleau, F.-X. and Samaran, F. (2018). Detection of mysticete calls: a sparse representationbased approach. Technical report, Institut Mines Télécom Atlantique.

Stafford, K. M., Bohnenstiehl, D. R., Tolstoy, M., Chapp, E., Mellinger, D. K., and Moore, S. E. (2004). Antarctic-type blue whale calls recorded at low latitudes in the Indian and eastern Pacific Oceans. Deep-Sea Research Part I: Oceanographic Research Papers, 51(10):1337-1346.

Stafford, K. M., Chapp, E., Bohnenstiel, D. R., and Tolstoy, M. (2011). Seasonal detection of three types of "pygmy" blue whale calls in the Indian Ocean. Marine Mammal Science, $27(4): 828-840$.

Stafford, K. M. and Moore, S. E. (2005). Atypical calling by a blue whale in the Gulf of Alaska (L). The Journal of the Acoustical Society of America, 117(5):2724-2727.

Stafford, K. M., Nieukirk, S. L., and Fox, C. G. (1999). Low-frequency whale sounds recorded on hydrophones moored in the eastern tropical Pacific. The Journal of the Acoustical Society of America, 106(6):3687-3698.

Stafford, K. M., Nieukirk, S. L., and Fox, C. G. (2001). Geographic and seasonal variation of blue whale calls in the North Pacific. Journal of Cetacean Research and Management, $3(1): 65-76$.

Thomisch, K., Boebel, O., Bachmann, J., Filun, D., Neumann, S., Spiesecke, S., and Opzeeland, I. V. (2019). Temporal patterns in the acoustic presence of baleen whale species in a presumed breeding area off Namibia. Marine Ecology Progress Series, 620(June):201-214.

Thomisch, K., Boebel, O., Clark, C. W., Hagen, W., Spiesecke, S., Zitterbart, D. P., and Van Opzeeland, I. (2016). Spatio-temporal patterns in acoustic presence and distribution of 


\section{Appendices}




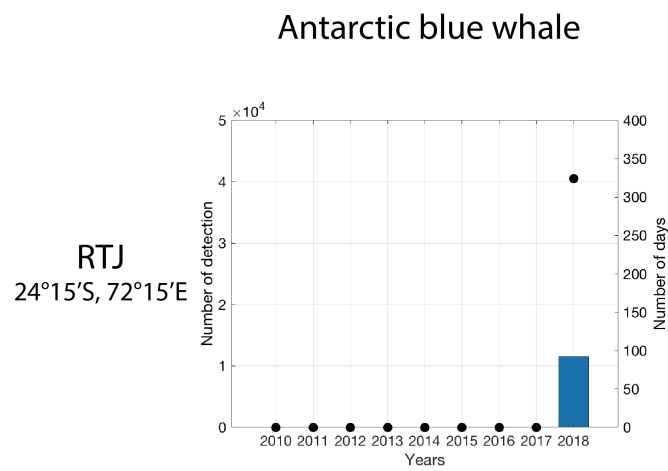

SEIO pygmy blue whale
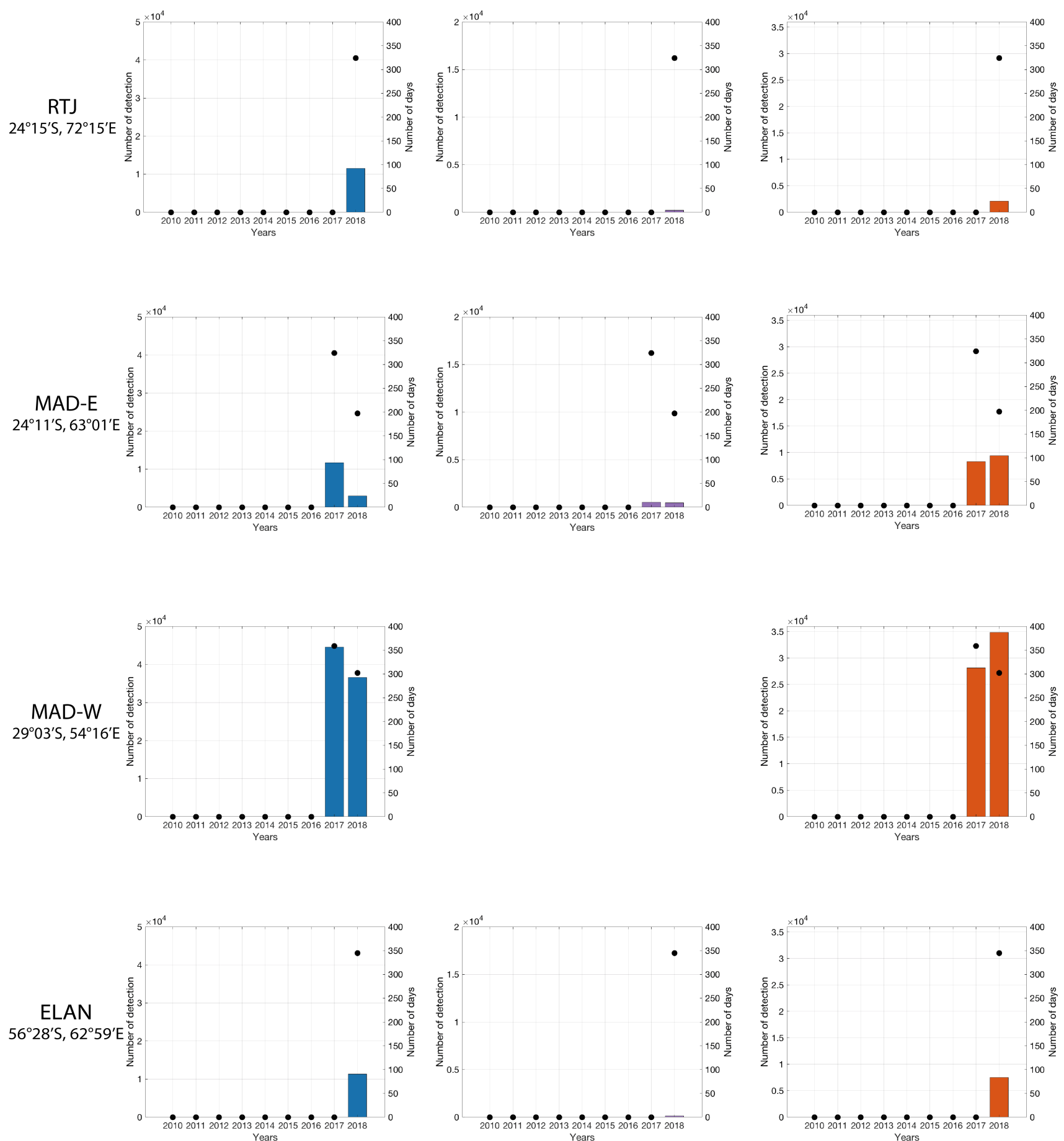

SWIO pygmy blue whale
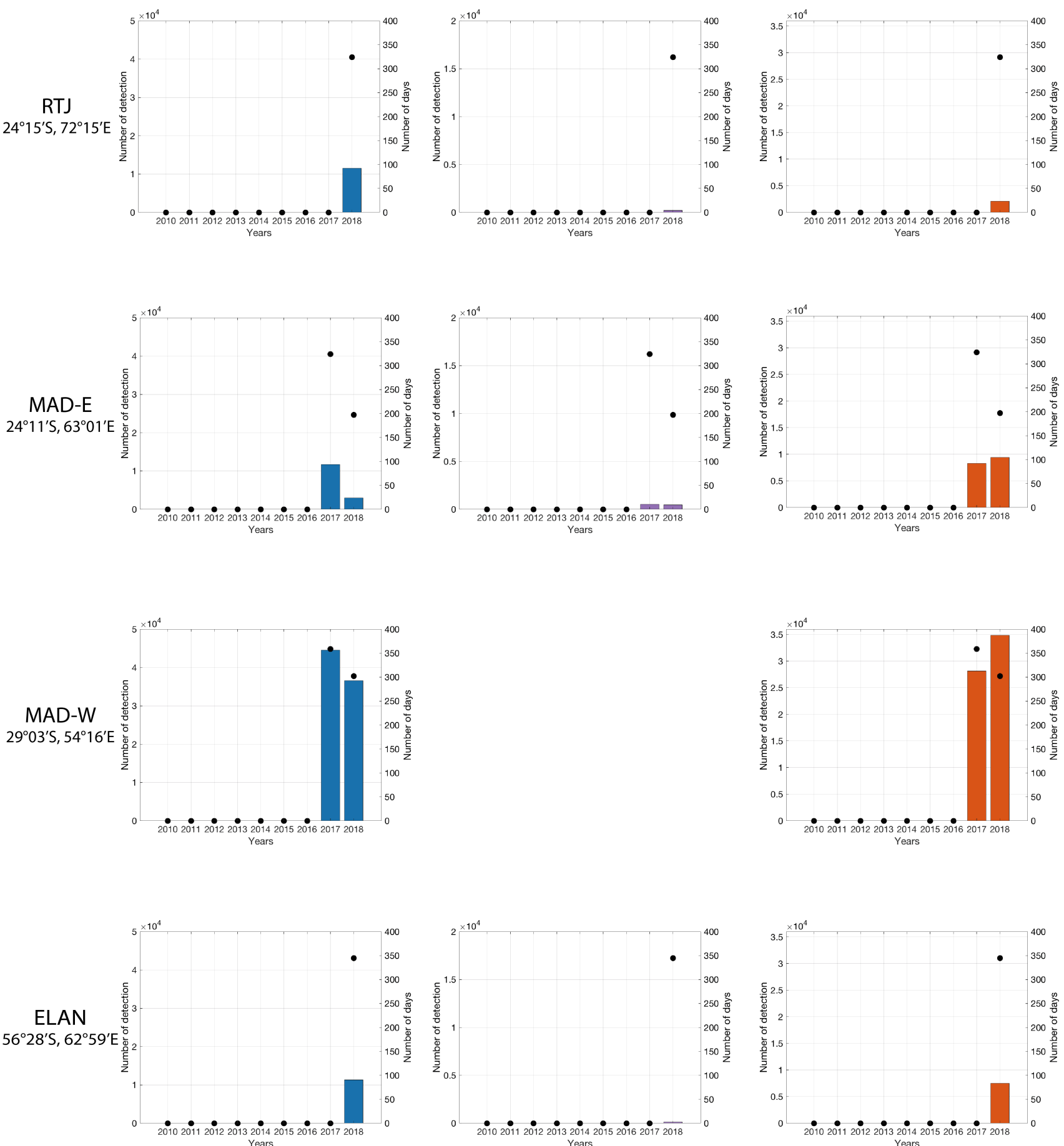

Appendix 1: Number of detected calls per year. Each row corresponds to a different site and each column to a different call type. Black dots represent the number of days of recording for each year. No SEIO pygmy blue whale calls were recorded at MAD-W, hence the absence of figure. 


\section{Antarctic blue whale}
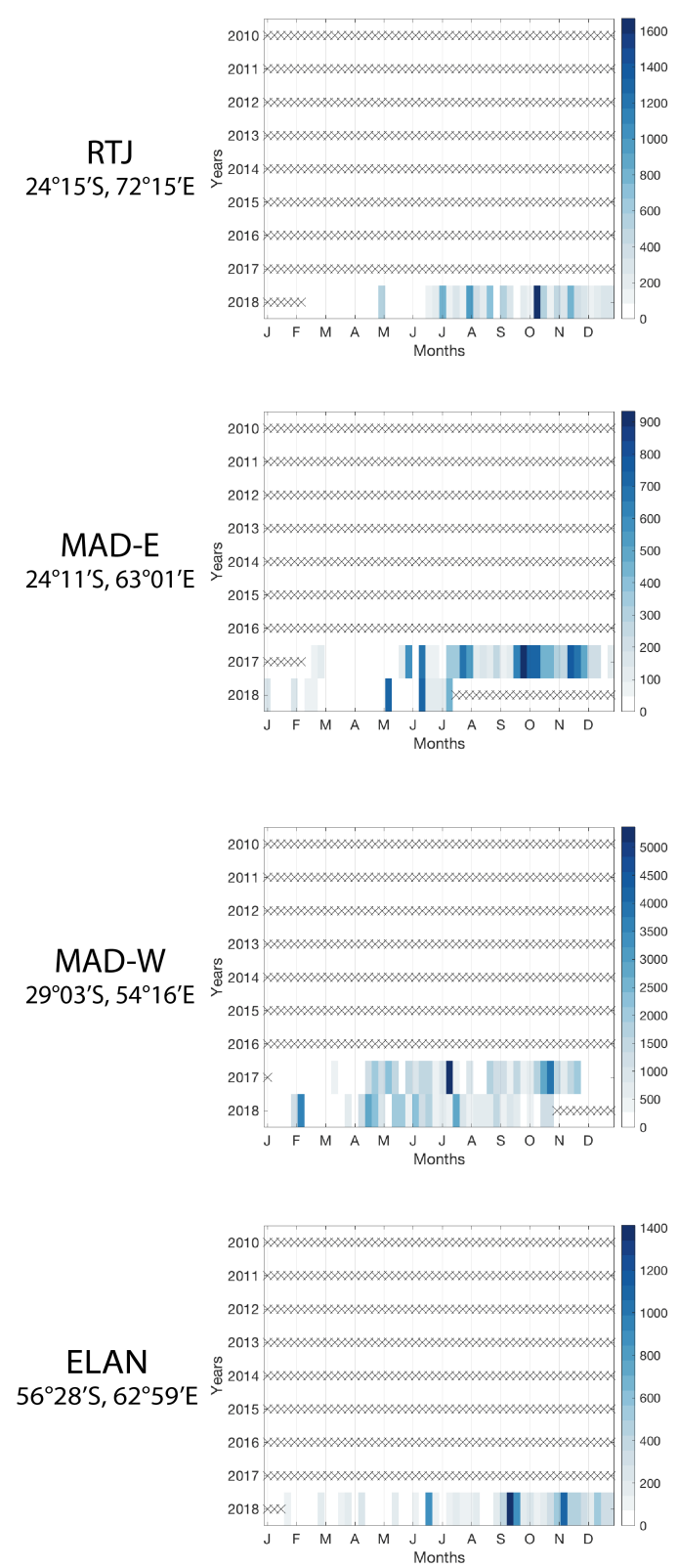

SEIO pygmy blue whale
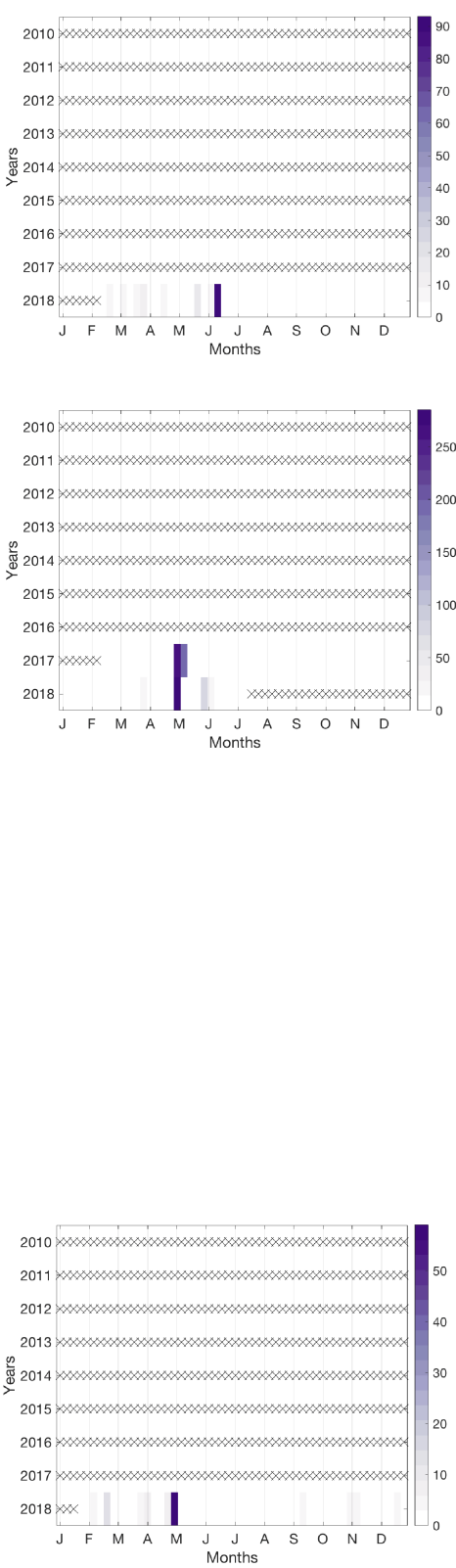
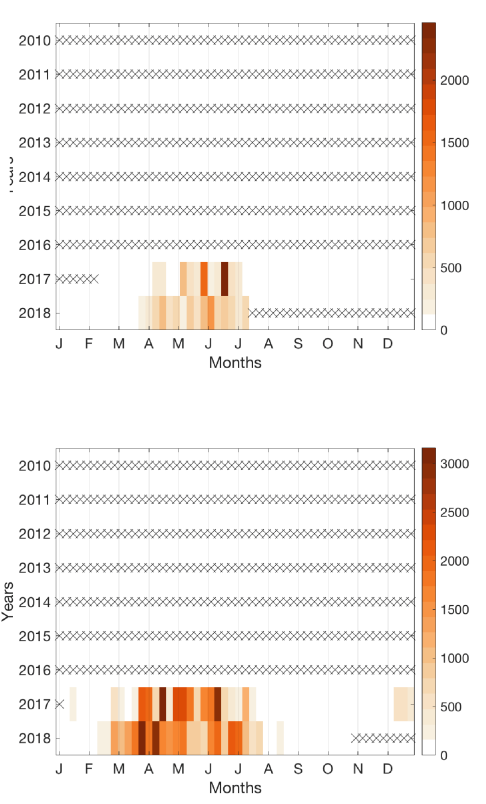

SWIO pygmy blue whale
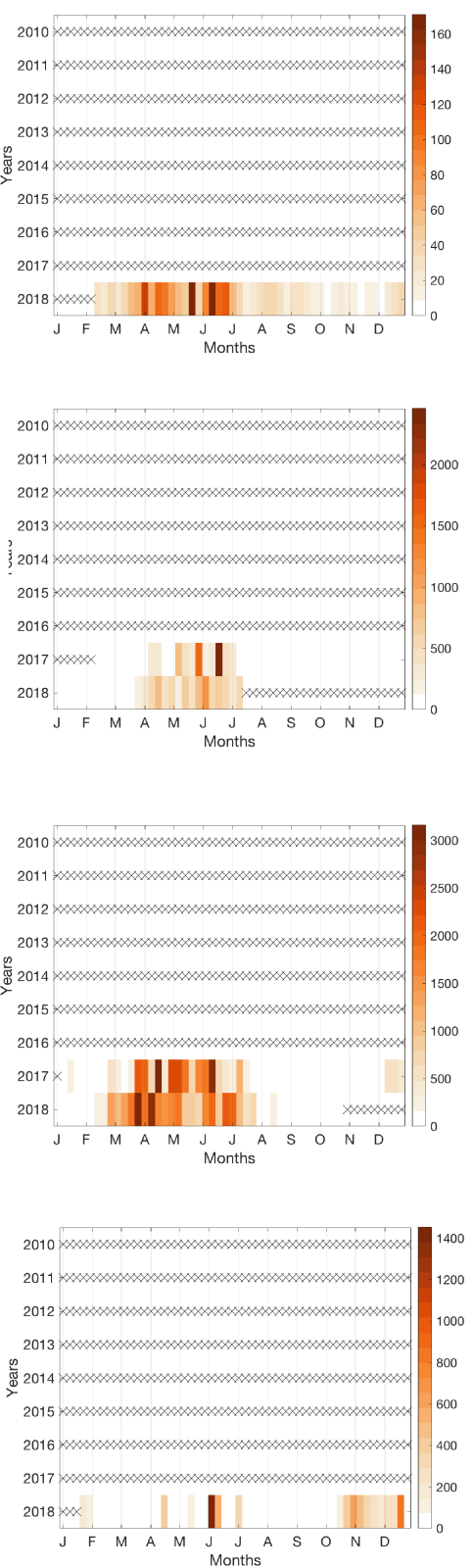

Appendix 2: Blue whale weekly acoustic presence. Each row corresponds to a recording site and each column to a blue whale call type. Each graph shows the density of calls per week (color intensity) for every month (x-axis) of the year in the y-axis. Note that the color scale is different for every graph). Weeks with fewer than 6 days of recordings are shown by X. Seasons are shown below the x-axis in different colors (summer: green, fall: orange, winter: blue, spring: pink). No SEIO pygmy blue whale calls were recorded at MAD-W, hence the absence of figure. 
Conceptualization : MT, KS, JYR, FS

Methodology : MT, FS, JYR

Software : MT

Formal analysis : MT

Investigation : MT, KS, FS, JYR

Writing - Original Draft : MT

Writing - Review \& Editing : MT, KS, FS, JYR

Visualization : MT

Project administration : JYR

Funding acquisition MT, FS, JYR 


\section{Declaration of interests}

$\bigotimes$ The authors declare that they have no known competing financial interests or personal relationships that could have appeared to influence the work reported in this paper.

$\square$ The authors declare the following financial interests/personal relationships which may be considered as potential competing interests: 